San Jose State University

SJSU ScholarWorks

Master's Theses

Master's Theses and Graduate Research

1995

\title{
Investigation of the folding of aminotyrosyl derivatives of bovine pancreatic ribonuclease $A$
}

Zenebe Nurga Asfir

San Jose State University

Follow this and additional works at: https://scholarworks.sjsu.edu/etd_theses

\section{Recommended Citation}

Asfir, Zenebe Nurga, "Investigation of the folding of aminotyrosyl derivatives of bovine pancreatic ribonuclease A" (1995). Master's Theses. 1113.

DOI: https://doi.org/10.31979/etd.askv-78z6

https://scholarworks.sjsu.edu/etd_theses/1113

This Thesis is brought to you for free and open access by the Master's Theses and Graduate Research at SJSU ScholarWorks. It has been accepted for inclusion in Master's Theses by an authorized administrator of SJSU ScholarWorks. For more information, please contact scholarworks@sjsu.edu. 


\section{INFORMATION TO USERS}

This manuscript has been reproduced from the microfilm master. UMI films the text directly from the original or copy submitted. Thus, some thesis and dissertation copies are in typewriter face, while others may be from any type of computer printer.

The quality of this reproduction is dependent upon the quality of the copy submitted. Broken or indistinct print, colored or poor quality illustrations and photographs, print bleedthrough, substandard margins, and improper alignment can adversely affect reproduction.

In the unlikely event that the author did not send UMI a complete manuscript and there are missing pages, these will be noted. Also, if unauthorized copyright material had to be removed, a note will indicate the deletion.

Oversize materials (e.g., maps, drawings, charts) are reproduced by sectioning the original, beginning at the upper left-hand corner and contimuing from left to right in equal sections with small overlaps. Each original is also photographed in one exposure and is included in reduced form at the back of the book.

Photographs included in the original manuscript have been reproduced xerographically in this copy. Higher quality $6^{\prime \prime} \times 9^{n}$ black and white photographic prints are available for any photographs or illustrations appearing in this copy for an additional charge. Contact UMI directly to order.

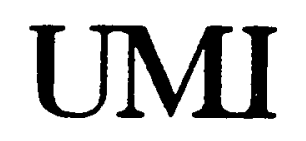

A Bell \& Howell information Company 300 North Zeeb Road. Ann Afbor. MI 48106-1346 USA 313:761-4700 800:521-0600 
- . 


\title{
INVESTIGATION OF THE FOLDING OF AMINOTYROSYL DERIVATIVES OF BOVINE PANCREATIC RIBONUCLEASE A
}

\author{
A Thesis \\ Presented to \\ The Faculty of the Department of Chemistry \\ San Jose State University
}

In Partial Fulfillment of

the Requirements for the Degree

Master of Science

By

Zenebe Nurga Asfir

August, 1995 
UMI Number: 1377204

Copyright 1995 by

Asfir, Zenebe Nurga

All rights reserved.

UMI Microform 1377204

Copyright 1996, by UMI Company. All rights reserved.

This microform edition is protected against unauthorized copying under Title 17, Onited States Code.

\section{UMI}

300 North Zeeb Road

Ann Arbor, MI 48103 
() 1995

Zenebe N. Asfir

ALL RIGHTS RESERVED 


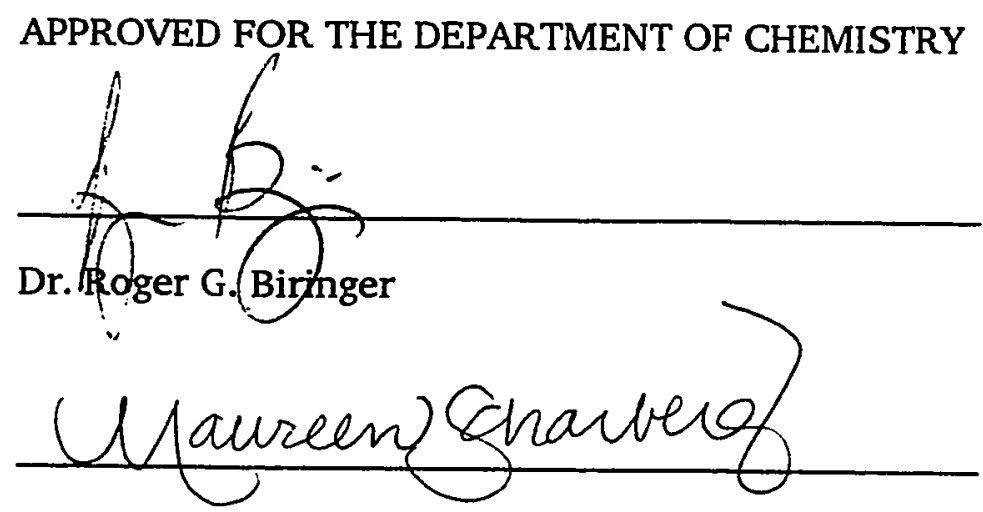

Dr. Maureen Scharberg

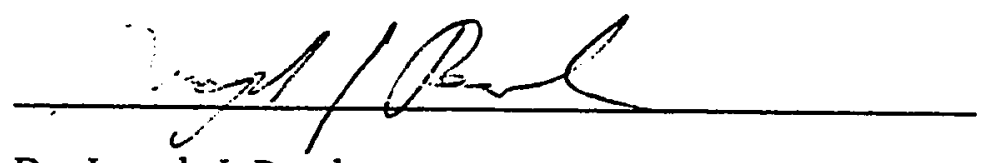

Dr. Joseph J. Pesek

APPROVED FOR THE UNIVERSITY

yerexe 2t. Etaxpore 


\begin{abstract}
INVESTIGATION OF THE FOLDING OF AMINOTYROSYL DERIVATIVES OF BOVINE PANCREATIC RIBONUCLEASE A (RNaSe A)

by Zenebe N. Asfir
\end{abstract}

The protein folding problem centers on the elucidation of how a protein attains its three dimensional structure. This project addresses the folding of specifically modified RNases. In previous kinetic studies of aminated derivatives of $\mathrm{RNase} A$ at $\mathrm{pH}^{*} 6$ and $-15^{\circ} \mathrm{C}$, unique kinetics were observed.

In this study, the subzero temperature study was extended to $\mathrm{pH}^{\star} 3$ and the underlying phenomena associated with the unique fluorescence increase previously observed at $\mathrm{pH}^{*} 6$ was examined. Previous attempts to study the folding kinetics in $\mathrm{pH}^{*} 3$ were complicated by reoxidation of the amino-derivatives. This problem has been successfully resolved. Vacuum degassing and nitrogen purging served the purpose. The kinetic results are significantly different from $\mathrm{pH}^{\star} 6$ results. Biphasic kinetic were found for both singly aminated and doubly aminated derivatives .

The cause for the unique fluorescence observed at $\mathrm{pH}^{*} 6$ is most likely due to fluorescence energy transfer from unmodified tyrosine residue to the aminotyrosine residue. Data for both model compounds and aminated RNases support this conclusion. 


\section{ACKNOWLEDGMENT}

I would like to thank my advisor, Dr. Roger Biringer for his patience, assistance and encouragement throughout my graduate research and study. I would like also to thank my committee members Dr. Maureen Scharberg and Dr. Joseph Pesek. Special thanks goes to Dr. Bradley Stone for evaluating my preliminary and final seminars and Dr. Pamela Stacks for her encouragement. I would also to thank the students in the lab for the friendly working atmosphere and cooperation. 
TABLE OF CONTENTS

Page

Abstract ... . . . . . . . . . . . . . . . . . iv

Acknowledgment . . . . . . . . . . . . . . . . . v

List of Tables .. . . . . . . . . . . . . . . . . . . ix

List of Figures . . . . . . . . . . . . . . . . .

List of Abbreviations . . . . . . . . . . . . . . . . xii

1. Introduction. . . . . . . . . . . . . . . . . . 1

1.1 Protein Structure . . . . . . . . . . . . . . . . 1

1.2 Protein Stability . . . . . . . . . . . . . . . . 2

1.3 General Aspects of Protein folding .. . . . . . . . . . . . . 3

1.3.1 Models of Protein Folding . . . . . . . . . . . . 5

1.3.2 Kinetics of Protein Folding. . . . . . . . . . . . 6

1.4 Kinetics of Refolding of RNase A . . . . . . . . . . . . 10

1.4.1 General Aspects . . . . . . . . . . . . . . . 10

1.4.2 The involvement of Proline Isomerization

in the Folding of RNase A. . . . . . . . . . . . . . . 11

1.4.3 Refolding Experiments at Subzero Temperature. . . . . 13

1.4.4 Aminotyrosyl RNase A. . . . . . . . . . . . . . 16

1.5 Goals of the Project . . . . . . . . . . . . . . . 19

2. Materials and Methods . . . . . . . . . . . . 20

2.1 Materials . . . . . . . . . . . . . . . . . 20

vi page 
2.1 .1 Reagents. . . . . . . . . . . . . . . 20

2.1.2 Equipment.. . . . . . . . . . . . . . . . 20

2.2 Methods .. . . . . . . . . . . . . . . . . . 21

2.2.1 Modification and Purification of RNase A. . . . . . . . 21

2.2.1.1 Synthesis and Purification of RNase A. . . . . . . . 21

2.2.1.2 Synthesis and Purification of Aminotyrosyl RNase A. . . . . 23

2.2.2 Deoxygenation protocol. . . . . . . . . . . . . 24

2.2.3 Refolding of Aminotyrosyl RNases. . . . . . . . . . 25

2.2.4 Guanidine Hydrochloride Denaturation of Amino RNases. . 26

2.2.5 Fluorescence Energy Transfer. . . . . . . . . . . 26

2.2.5.1 Model Compounds. . . . . . . . . . . . . . 25

2.2.5.2 Aminated RNases. . . . . . . . . . . . . . . 27

3. Results and Discussion . . . . . . . . . . . . . . 28

3.1 Deoxygenation. . . . . . . . . . . . . . . . . 28

3.2 Guanidine Hydrochloride Unfolding of $\mathrm{C}^{\varepsilon 115-\mathrm{NH}_{2}} \mathrm{RNase} \mathrm{A}$ and $\mathrm{C}^{\varepsilon 115,76-\mathrm{NH}_{2} \text { RNase } \mathrm{A}}$. . . . . . . . . 30

3.3 Folding of $\mathrm{C}^{\mathrm{E115}-\mathrm{NH}_{2}} \mathrm{RNase} \mathrm{A}$

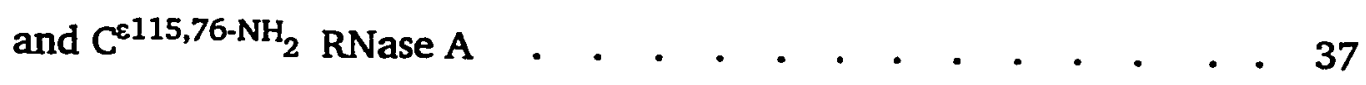

3.4 Fluorescence Energy Transfer . . . . . . . . . . . . . 45

3.4.1 Model Compounds . . . . . . . . . . . . . 46

3.4.2 Aminotyrosyl RNases . . . . . . . . . . . . . . 49 
page

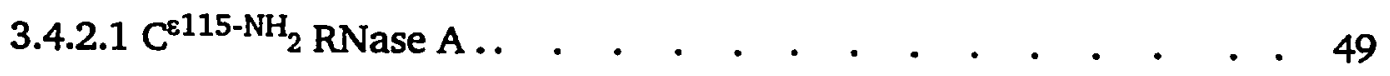

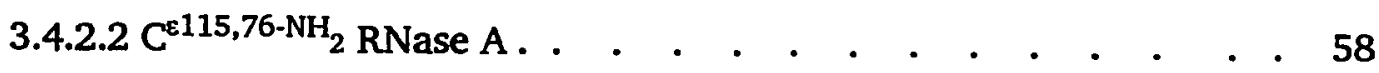

4. Conclusion. . . . . . . . . . . . . . . . . . . 61

References .... . . . . . . . . . . . . . . . . . 63

viii 


\section{List of Tables}

Table

Page

1. Folding kinetics for RNase $\mathrm{A}$ and nitro-derivatives of $\mathrm{RNase} \mathrm{A}, \mathrm{pH}^{*} 3 . \quad 15$

2. Folding kinetics for amino-derivatives of RNase A. . . . $\quad$ - 42 


\section{List of Figures}

Figure Page

1. Dependence of heat capacity on temperature in different aqueous solutions for hen egg-white lysozyme . . . . . . . 4

2. Hypothetical reaction coordinate for a simple sequential

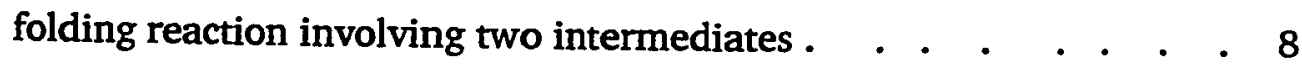

3. Folding kinetics for $\mathrm{C}^{\varepsilon 115-\mathrm{NH}_{2}} \mathrm{RNase} \mathrm{A}$

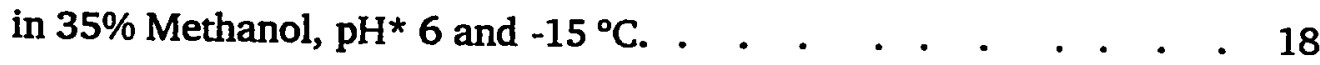

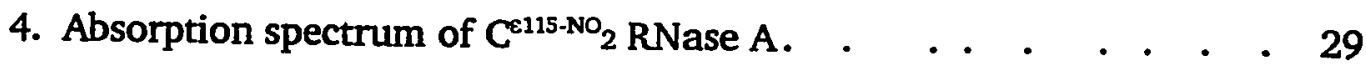

5. Absorption spectrum of $\mathrm{C}^{\varepsilon 115-\mathrm{NH}_{2}}$ RNase $\mathrm{A}$,

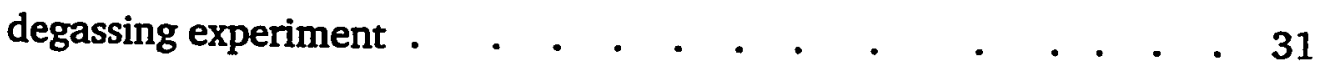

6. Absorption spectrum of Refolded $\mathrm{C}^{\varepsilon 115,76-\mathrm{NH}_{2}}$ RNase A,

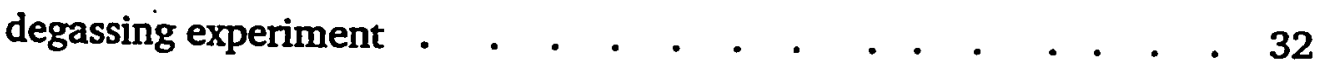

7. Absorption spectrum of refolded $\mathrm{C}^{\varepsilon 115-\mathrm{NH}_{2}}$ RNase A,

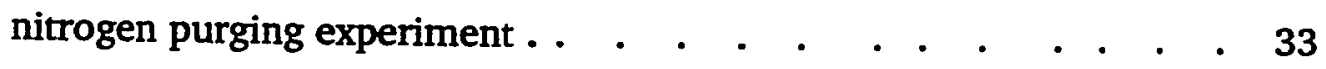

8. Absorption spectrum of refolded $C^{\varepsilon 115,76-\mathrm{NH}_{2}}$ RNase $A$,

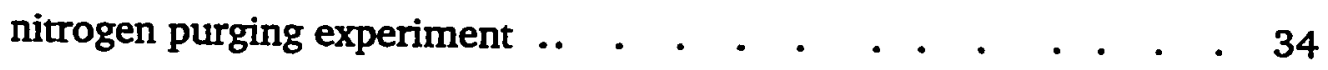

9. Guanidine hydrochloride unfolding of aminated RNases . . . . 35

10. The fluorescence spectra of $\mathrm{C}^{\varepsilon 115-\mathrm{NH}_{2}} \mathrm{RNase} A$

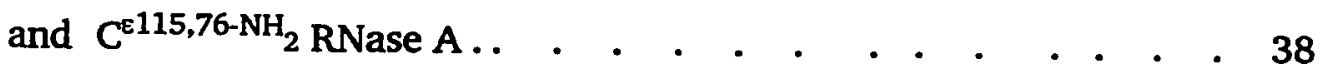


Figure

Page

11. Time dependent changes in the folding of $\mathrm{C}^{\varepsilon 115-\mathrm{NH}_{2}}$ RNase $\mathrm{A}$. . . 40

12. Time dependent changes in the folding of $\mathrm{C}^{\varepsilon 115,76-\mathrm{NH}_{2}} \mathrm{RNase} \mathrm{A}$. . $\quad 41$

13. Excitation spectra of model compounds . . . . . . . . . 47

14. Emission spectra of model compounds . . . . . . . . . . 48

15. Excitation spectra of $\mathrm{C}^{\varepsilon 115-\mathrm{NH}_{2}} \mathrm{RNase}$ A. . $\quad . \quad$. . . . . . $\quad$. 50

16. Emission spectra of $\mathrm{C}^{\varepsilon 115,76-\mathrm{NH}_{2}} \mathrm{RNase}$ A. . . . . . . . $\quad$. 51

17. Excitation spectra of aminotyrosine. . . . . . . . . . . 53

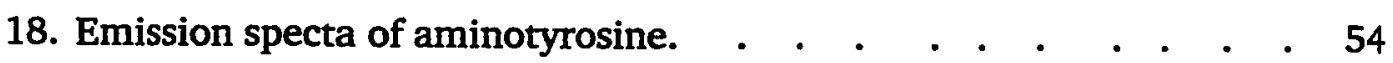

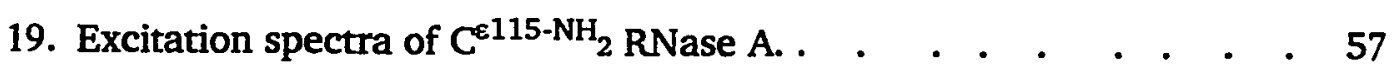

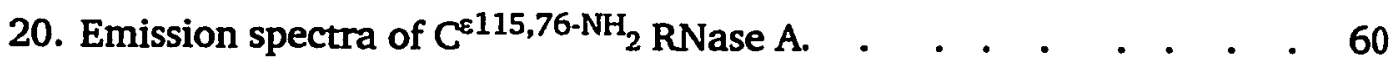


List of Abbreviations

$\mathrm{C}^{\mathrm{E} 115-\mathrm{NH}_{2}} \mathrm{RNase} \mathrm{A}: \quad$ tyrosine-115 aminated at the $\varepsilon$ position in RNase A

$\mathrm{C}^{\varepsilon 115,76-\mathrm{NH}_{2}}$ RNase A: tyrosine-115 and tyrosine-76 aminated at the $\varepsilon$ position in RNase $\mathrm{A}$

$\mathrm{C}^{\varepsilon 115-\mathrm{NO}_{2}}$ RNase A: tyrosine-115 nitrated at the $\varepsilon$ position in RNase A

$\mathrm{C}^{\varepsilon 115,76-\mathrm{NO}_{2}}$ RNase A: tyrosine-115 and tyrosine-76 nitrated at the $\varepsilon$ position in RNase A

$\mathrm{CD}: \quad \quad$ circular dichroism

HEPES: $\quad$ N-2-Hydroxyethylpiperazine-N'-2-ethane sulfonic acid

IEF : $\quad$ isoelectric focusing

I : $\quad$ an intermediate state

$\mathrm{N}: \quad$ native state

NMR : $\quad$ nuclear magnetic resonance

RNase A : $\quad$ bovine pancreatic ribonuclease A

TNM : $\quad$ tetranitromethane

$\mathrm{U}: \quad \quad$ Unfolded state 


\section{INTRODUCTION}

\subsection{Protein Structure}

There are $20 \alpha$-amino acids that are commonly used as the building blocks of proteins. The order of the amino acids in the linear polyamide chain for any given protein is known as the primary structure or primary sequence of the protein. The spacial arrangement of the primary structure into structural motifs through local hydrogen bonds is known as the secondary structure; $\alpha$-helx, $\beta$-strands, random coil, $\beta$-turns are the major types of secondary structure. The next hierarchy in protein structure is the tertiary structure, which describes the three dimensional packing of the secondary structure. Many proteins are comprised of more than one polypeptide chain. The relative three-dimensional arrangement of these independently folded chains (subunits) is known as the quaternary structure.

The primary sequence of a protein is relatively easy to determine, but it is a challenge for researchers to determine the three dimensional structure. There are three approaches commonly used for determining the structure of proteins. X-ray crystallography (Hendrickson, 1987), the first approach, is the most reliable method. The main problem with this method is that not all proteins form crystals and crystals are required for such measurements. Although limited, this technique provides the database upon which the following two techniques are based. The second one employs computation methods. Chou and Fasman (1978) developed a method to determine which portions of the primary sequence would 
adapt $\alpha$-helices and $\beta$-strands by assigning a $\alpha$-helix and $\beta$-sheet propensity to each amino acid along the polypeptide chain. The propensity is based on $\mathrm{x}$-ray data and reflects the frequency that a particular amino acid occurs in an $\alpha$-helix or $\beta$-sheet in the $x$-ray database. The accuracy of this technique is slightly better than 50\%. Dubachack et al. (1993) have used computer-simulated neural networks to predict the three-dimensional structure of proteins. The networks were trained on the known crystal structures and sequences of proteins. The trained neural network was then used to classify proteins in terms of structure (folding classes). The folding classes employed were: four helix bundles, parallel $(\alpha / \beta)_{8}$ barrels, nucleotide binding fold, immunoglobulin fold and a none of these category. The authors claim a $87 \%$ accuracy for the prediction of closely related proteins.

The third approach is based on empirical methods such as circular dichroism (CD), Fourier transform infrared spectroscopy (FTIR) and NMR. The spectra obtained from CD, NMR and FTIR measurements give the average signals of all secondary structures present. Several attempts have been made to evaluate these data in terms of the contribution of each secondary structure to the spectra: CD (Stokkum et al., 1990), FTIR (Dousseau and Pezolet, 1990), and the combined CD and FTIR spectra (Pribic et al., 1993). The prediction results strongly depend on the various algorithms used to analyze the data.

\subsection{Protein Stability}

Privalov and Gill (1988) have discussed the various factors that affect 
protein stability. Dipole-dipole interaction, Van der Waal's forces, the hydrophobic effect, and hydrogen bonding all play an important role in protein stability. Historically, the contribution of electrostatic forces has been considered to be minimal because there are few salt bridges in the average protein. This has recently been called into question by Hendsch and Tidor (1994). They suggest that although these interactions are individually weak in aqueous solutions, together, they act cooperatively to stabilize the native protein structure.

The stability of proteins is best understood by comparing the thermodynamics of the native protein and unfolded protein. It has been found that the native structure of proteins is only marginally more stable than the unfolded state (Privalov, 1979), typically only 20 to $40 \mathrm{~kJ} / \mathrm{mol}$. In addition, the entropy and enthalpy of unfolding are temperature dependent, because the heat capacity of the unfolded state is significantly greater than the heat capacity of the .folded state (Privalov, 1979). As illustrated in Figure 1 (Privalov and Khechinashvili, 1974), this results in a temperature dependence of the free energy of stabilization where the maximum stability is reduced both at low and high temperatures. In the range where the heat capacity changes, the enthalpy and entropy of unfolding are large and positive. A large entropy is expected for the unfolded state because of higher degree of freedom.

\subsection{General Aspects of Protein Folding}

The amino acid sequence of a protein is incoded by DNA. After its production on the ribosomes, the nascent polypeptide folds spontaneously to the 


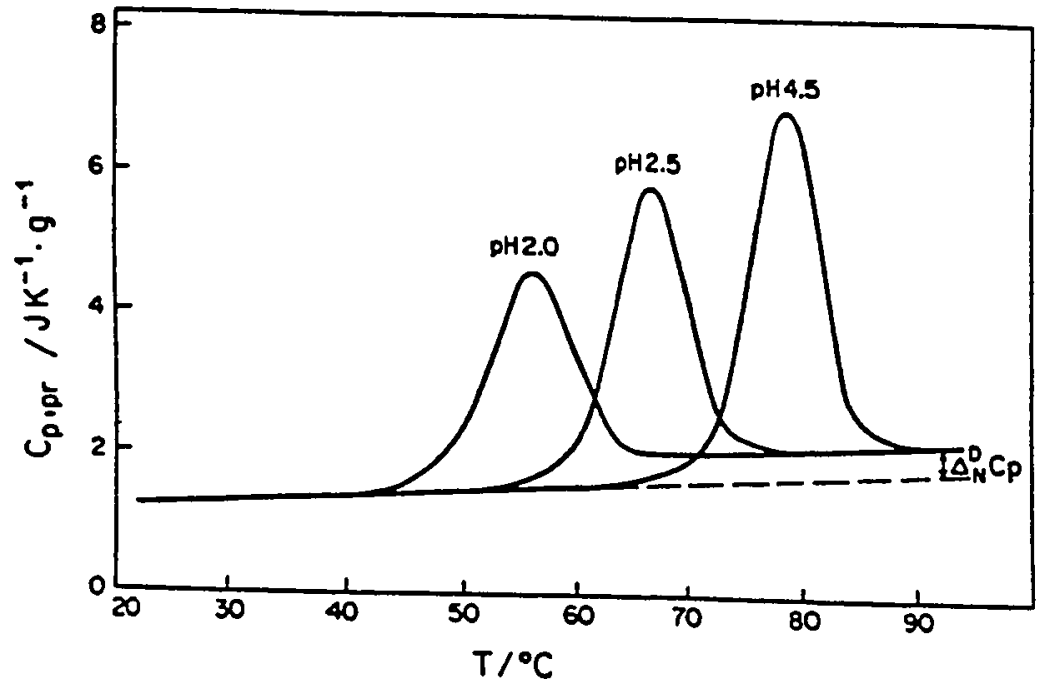

FIGURE 1 : Dependence of heat capacity on temperature in different aqueous solutions for hen egg-white lysozyme. The maximum of the heat absorption peak corresponds to the midpoint of transition.

(taken from Privalov and Khechinashvili, 1974). 
biologically competent native state. The process by which this occurs is not well understood and is commonly referred to as the protein folding problem. X-ray crystallographic studies have shown that proteins with the same sequence have the same three-dimensional structure, proteins with similar sequences have similar structures, and proteins with different sequences have different structures. From these observations, the central dogma of protein folding was developed which states that "the sequence of a protein defines its three dimensional structure."

\subsubsection{Models of Protein Folding}

There are several models that have been developed over the years to describe the protein folding process. Three of these are examined below.

One of the first models to be proposed is known as the random search model (Levinthal, 1968). This model assumes that the protein searches all possible conformations to find that structure with the global minimum in free energy. Levinthal examined this model by calculating the time it would take for a protein to fold in this way and found that it would take much too long to complete. For example, if a protein has 100 residues, the minimum number of conformations it may have is $2^{100}$ which is equivalent to $1.3 \times 10^{30}$. Assuming diffusion control, the fastest rate possible, it would take approximately $10^{50}$ years to search all conformations.

Another model is Wetlaufer's nucleation rapid growth model (1973). This model assumes that nucleation centers, small units of ordered structure, are 
formed slowly and complete folding follows rapidly. This requires that the formation of the "nuclei" is the rate limiting step and thus no intermediates are populated between nucleation center and the native protein. There is no explanation and experimental support for how the nucleation center is formed.

The currently favored model is known as the framework model (Kim and Baldwin, 1982). This model assumes that folding goes through a series of structural intermediates and does so in sequential manner. There is a significant amount of experimental support for this model in the literature.

\subsubsection{Kinetics of Protein Folding}

One approach used to examine the protein folding problem involves the study of the kinetics of the folding process. Such studies provide information about the rate of the folding process and can indicate if intermediates are involved. Careful examination of the results enable one to postulate possible reaction mechanisms.

Folding may be either thermodynamically controlled, kinetically controlled or a combination of the the two. In case of pure thermodynamic controlled folding that proceeds through intermediate states (framework model), only the most stable intermediate states will be populated. In case of pure kinetic controlled folding, the population of the intermediates is governed by the activation free energy between the individual intermediates. The difference between these control mechanisms is best understood by example. Consider the simple folding pathway 


$$
\text { D-----> } \mathrm{I}_{1}----->>\mathrm{I}_{2}----->\mathrm{N}
$$

where $D$ is the denatured state, $N$ is the native state, and $I_{1}$ and $I_{2}$ are intermediates along the folding pathway. Also, assume that the idealized energy diagram for this pathway given in Figure 2. For pure thermodynamic control, only $I_{1}$ will be populated because it has a lower free energy content than $I_{2}$. For kinetic control, $\mathrm{I}_{2}$ will be highly populated due to high activation energy barrier between this intermediate state and the native state. In this case, the rate of decomposition rather than the stability of the intermediate plays more important role in determining the population of intermediate states. In cases where both thermodynamic and kinetic control are significant, both $I_{1}$ and $I_{2}$ may be highly populated. Experimental data for small globular proteins supports a combination of kinetic and thermodynamic control.

In order to examine the folding of a protein, it must first be unfolded chemically or thermally. Refolding of a protein is accomplished by dilution of the chemical denaturant or by lowering the temperature to conditions that favor the native state. Unfolding may be examined in the reverse manner.

The kinetics of folding is studied by following the changes in some property of the protein as a function of time as the protein folds or unfolds. Properties are typically measured with spectroscopic methods that are sensitive to the structural state of the protein. NMR, absorbance, fluorescence and circular dichroism are the most widely used techniques.

Ultraviolet absorption spectroscopy provides information about global 


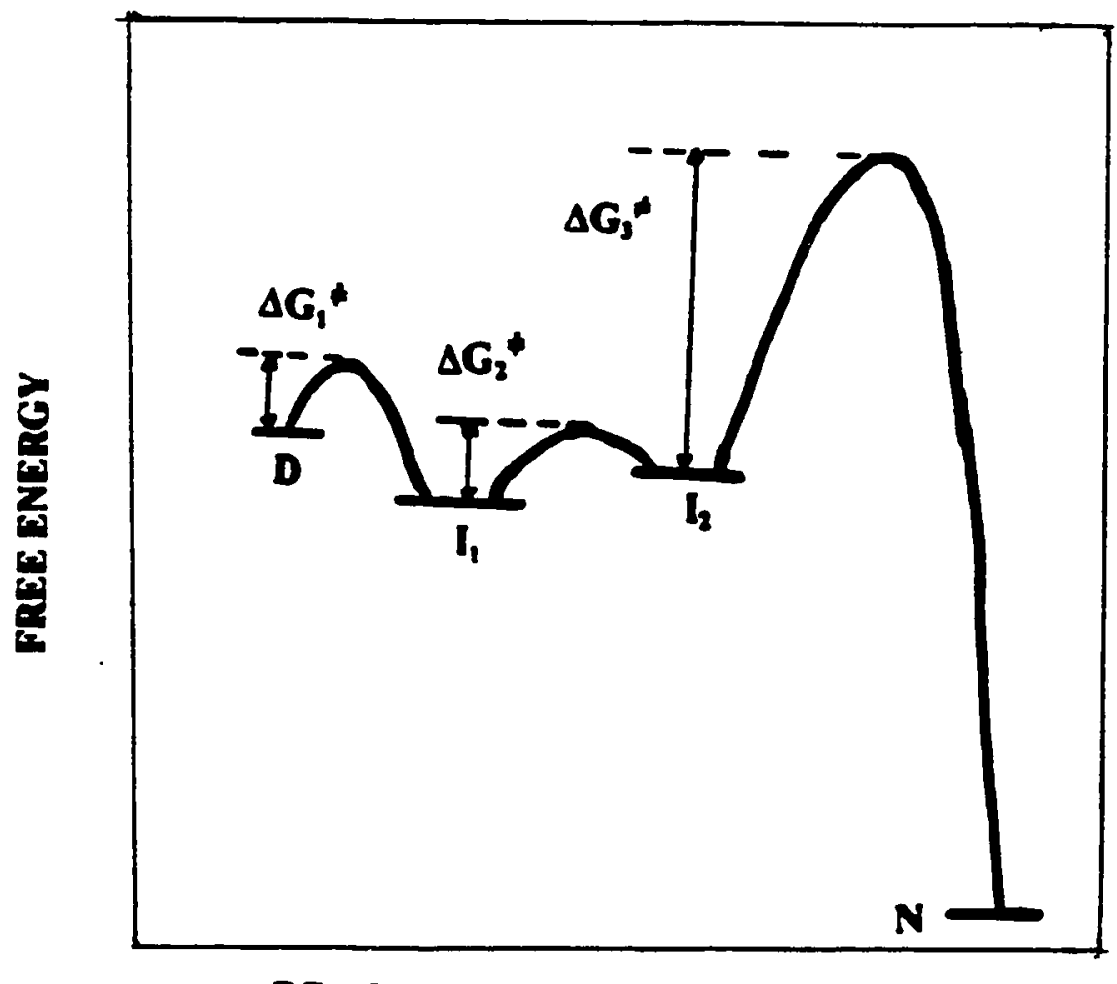

REACTION COORDINATE

FIGURB 2 : Hypothetical reaction coordinate for a simple sequential folding reaction involving two intermediates, $I_{1}$ and $I_{2} . D$ and $N$ represent the denatured and native state respectively. 
changes in the tertiary structure of the protein. The aromatic residues (tryptophan and tyrosine) are the intrinsic chromophores in proteins that are typically monitored. In a typical folding experiment, absorbance is monitored at a wavelength to the "red" of the absorbance maximum. This will yield an increase in an absorbance as the protein folds. This is due to the fact that, in most cases, the entire absorption band undergoes a bathochromic shift as the protein folds to its native state. This results from the changes in the polarizabilty of the microsolvent environment. In addition, the intensity of the absorbance of the folded protein is higher than the unfolded state because the chromophores are usually shielded from solvent (Schmid, 1981). The exclusion of water results in an increase in the absorbance.

Fluorescence spectroscopy is also widely used to monitor global changes in the tertiary structure of proteins. Tyrosine and tryptophan fluorescence are important for this purpose. Fluorescence has a significant advantage over absorbance spectroscopy, as it is more sensitive to environmental changes because of the longer life time of the excited state. Typically, the intrinsic fluorescence of a protein decreases as the protein folds, as quenching in native state is usually greater than quenching in unfolded state.

The signals measured by the spectroscopic probes discussed above give the average spectra for all contributing chromophores or fluorophores. Thus, only a global picture of the folding process can be obtained. However, information about what is taking place in a specific region during folding can be obtained by chemical modification of specific residue(s) in specific regions in the protein to 
yield unique chromophores or fluorophores. Examples of such modifications have been reported for RNase A by Garel and Baldwin (1975), Biringer and Fink (1988a), and Puntambekar (1991).

\subsection{Kinetics of Refolding of RNase $A$}

\subsubsection{General Aspects}

Bovine pancreatic ribonuclease A (RNase A), a small globular protein, comprises 124 amino acid residues. It contains six tyrosines, three of which are buried in structure (Tyr-25, $-92,-97)$ and three of which are solvent exposed (Tyr-73, -76, -115). These residues are, as will be seen later, very important in the kinetic study of RNase A folding. RNase A has four prolines, two of which are in the trans configuration in native protein and two of which are in the cis configuration in native protein. Both Pro-93 and Pro-114 are in the cis configuration in the native state, but are found as an equilibrium mixtures of both cis and trans in denatured state. Pro-93 and Pro-114 are the subject of several discussions regarding the slow folding kinetics of RNase A.

It has been shown that unfolded RNase A consists of a fast folding species $U_{F}(30 \%)$ and a slow folding species $U_{S}(70 \%)$ (Garel and Baldwin, 1973). It has been found that the $U_{s}$ species consists of two distinct populations of molecules (Schmid and Blaschek, 1981). One population, the major species $\left(U_{s} "\right)$, represents $50 \%$ of the folding species and the second, the minor species $\left(U_{s}^{\prime}\right)$, represent $20 \%$ of the folding species. There is considerable experimental evidence that $U_{s}^{\prime}$ folds slowly because it contains an incorrect geometric isomer 
for a Xaa-Pro peptide bond ( Brandts et al., 1975). The Xaa-Pro peptide bond is a peptide bond where the proline is covalently attached to any amino acid Xaa through its iminonitrogen. The minimal model for the folding of RNase A is thus,

$$
\begin{aligned}
& \mathrm{U}_{\mathrm{F}} \text {------fast---.----->N } \quad 30 \% \\
& \mathrm{U}_{\mathrm{s}}{ }^{\prime \prime} \text { - ----slow-------->N } \quad 50 \% \\
& U_{s}{ }^{\prime} \text {----very slow ----- }>N \quad 20 \%
\end{aligned}
$$

where $\mathrm{N}$ is the native state.

RNase A is an ideal model for protein folding studies. Some of the features RNase A that make attractive are: 1) its three-dimensional structure is known, 2) it is soluble both in water and organic solvents, 3 ) it tends not to aggregate, 4) unfolding and refolding are reversible in most conditions, and 5) it has been well studied (Garel and Baldwin, 1973, Adler and Scheraga, 1990, Biringer and Fink, 1988 a-c, Lin and Brandts, 1983, Schmid, 1981, etc.).

1.4.2 The Involvement of Proline Isomerization in the Folding of RNase A While the factors that allow the fast folding species $\left(U_{\mathrm{g}}\right)$ to fold fast are not known, the reason for the retarded time-scale of $U_{s}$ folding is believed to be isomerization about one or more proline imide bonds. RNase A has four prolines. Pro-42 and Pro-117 are in the trans conformation in both native and unfolded state (Lin and Brandts, 1984). Pro-93 and Pro-114 are in cis conformation in native protein, but exist as a mixture of cis and trans in the unfolded state. 
Brandts et. al (1975) have suggested that the isomerization of prolines to the correct conformation results in the formation of a fast folding species $\left(U_{F}\right)$ which can then rapidly fold to the native state.

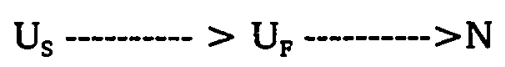

Other researchers (Cook et al., 1979; Schmid and Blaschek, 1981), however, found that the major folding species of RNase A folds first to a native like intermediate, $\mathrm{I}_{\mathrm{N}}$, before isomerization of proline to native conformation occurs.

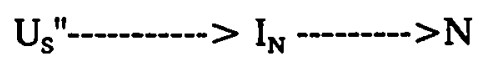

Since it is known that the slow folding species of RNase A is caused by cis to trans isomerization of either Pro-93 or both Pro-93 and Pro-114, it is important to know the trans to cis ratio for both Pro-93 and Pro-114 in the unfolded protein. The literature contains contradicting results regarding the ratio of trans to cis proline in unfolded state. Lin and Brandts used isomer specific proteolysis (ISP) $(1983,1984)$ and found that $70 \%$ of proline 93 and $95 \%$ of Pro-114 are in the cis conformation in urea unfolded protein. Adler and Scheraga (1990), using NMR, found that $40 \%$ of Pro-93 and $37 \%$ of Pro-114 in the cis conformation in heat unfolded RNase A. Biringer and Puntambekar (1991) used nitrotyrosyl derivatives of RNase A as NMR probes and found that $55 \%$ of Pro-114 is in the cis configuration in thermally denatured RNase A and $38 \%$ of Pro-114 is in the cis 
configuration in guanidine hydrochloride unfolded RNase A.

Many studies suggest the involvement of proline 93 in the slow folding process of RNase A. Lin and Brandts (1983) used ISP to show that the slowest phase in the refolding of RNase A is rate limited by isomerization of Pro-93. Schmid and Blaschek (1981) and Biringer and Fink (1988c) have shown that Pro-93 isomerizes only after the formation of a native like intermediate in the slow folding pathway.

Confirmation of the involvement of both Pro-93 and Pro-114 in the slow folding of RNase A is found in the site-directed mutagenesis experiments done by Baldwin et al. (1992). In their study, they individually replaced Pro-93 with alanine and with serine and Pro-114 was replaced with a variety of different amino acids. They have also prepared a mutant by which both Pro-93 and Pro-114 were replaced by other amino acids. Based on the results of folding studies of these mutants, the authors concluded that the isomerization of both Pro-93 and Pro-114 are involved in the slow folding process.

\subsubsection{Refolding Experiments at Subzero Temperature}

Biringer et al. (1982; 1988a, b, c) have investigated the folding of RNase A in methanol cryosolvent $(35 \% \mathrm{v} / \mathrm{v})$ at subzero temperature $\left(-15^{\circ} \mathrm{C}\right)$ using a number of techniques. Absorbance, fluorescence and NMR monitored folding of RNase A showed multiphasic kinetics which are consistent with an intermediate controlled folding pathway. However, the number of kinetic phases as well as the rate constants and amplitudes were dependent of the type of probe and condition 
of folding. Although informative, the results provide only a crude picture of the folding process.

In order to add more detail to the proposed mechanism, Biringer and Fink (1988a) modified three of the six tyrosine residues of RNase A and studied the refolding kinetics in aqueous / methanol, at $-15{ }^{\circ} \mathrm{C}$ and at $\mathrm{pH}^{\star} 3$ and 6 . In

particular, $C^{\varepsilon 115-\mathrm{NO}_{2}}$ RNase A, $C^{\varepsilon 115,76-\mathrm{NO}_{2}}$ RNase A, and $C^{\varepsilon 115,76,73-\mathrm{NO}_{2}}$ RNase A were prepared in which tyrosine 115, tyrosines 115 and 76 , and tyrosines 115, 76 and 73 are nitrated at $\varepsilon$ position respectively. The kinetics were monitored by absorbance at $300 \mathrm{~nm}$ where only the nitrated tyrosines absorb. Biphasic kinetics were observed for $\mathrm{C}^{\varepsilon 115-\mathrm{NO}_{2}} \mathrm{RNase} A$ and triphasic kinetics were observed for the other derivatives under all experimental conditions. These results and those discussed earlier suggest that different regions of the protein attain a native environment at different rates. The results of this study and of the other probes are summarized in Table 1 for comparison.

By analyzing the results of folding of unmodified and modified RNase A in methanol cryosolvent, Biringer and Fink (1988c) proposed a model with multiple intermediates and parallel folding pathway. 
TABLE I : Kinetics of Folding of RNase A at $-15^{\circ} \mathrm{C}$ in $35 \%$ Methanol at $\mathrm{pH}^{\star} 3$

\begin{tabular}{lllll}
\hline & $k_{1}$ (AMP) & $k_{2}$ (AMP) & $k_{3}$ (AMP) & $k_{4}$ (AMP) \\
& $\times 10^{2}$ & $\times 10^{2}$ & $\times 10^{3}$ & $\times 10^{4}$ \\
\hline $\mathrm{A}_{286}$ & 6.2 & $1.3(19)$ & $1.7(19)$ & $2.9(19)$ \\
fluorescence &.-- & -- & $1.3(17)$ & $3.0(7)$ \\
$115-\mathrm{NO}_{2}$ & 2.6 & $0.88(37)$ & $-\ldots$ & $\ldots$ \\
$115,76-\mathrm{NO}_{2}$ & 2.3 & $1.4(37)$ & $0.82(9)$ & \\
$115,76,76-\mathrm{NO}_{2}$ & 3.0 & $0.8(26)$ & $1.3(18)$ & \\
& & & &
\end{tabular}

The values in the parentheses are the amplitudes expressed as a percentage of the total amplitude change between unfolded and native states. $115-\mathrm{NO}_{2}$, $115,76-\mathrm{NO}_{2}, 115,76,76-\mathrm{NO}_{2}$ represent singly, doubly and triply nitrated derivatives of RNase A respectively (taken from Biringer and Fink, 1988c). 


$$
\begin{aligned}
& U_{F}---k--->N \\
& U_{S}^{\prime \prime}--k_{1}-->I_{1}^{\prime}--k_{2}-->I_{2}^{\prime}--k_{3}^{\prime}-->N \\
& U_{S}^{\prime}--k_{1}-->I_{1}--k_{2}-->I_{2}--k_{3}-->I_{3}--k_{4}->N
\end{aligned}
$$

They suggest that the major folding pathway $\left(\mathrm{U}_{\mathrm{s}}{ }^{\prime \prime}\right)$ does not involve proline isomerization because the rate of the slowest process $\left(\mathrm{k}_{3}^{\prime}\right)$ is $\mathrm{pH}$ dependent. Instead, they concluded that the minor folding pathway $\left(U_{s}^{\prime}\right)$ involved the isomerization of Pro-93.

It is of particular interest that the environment about Tyr-115, as judged by

the folding kinetics of $\mathrm{C}^{\varepsilon 115-\mathrm{NO}_{2}}$ RNase $\mathrm{A}$, becomes native-like at one of the fastest rates observed in these studies. Since Tyr-115 is adjacent to Pro-114, it should be sensitive to the conformational state of Pro-114. The fact that proline isomerization is associated with a high activation energy indicates that such events should produce slow kinetics. Therefore, this data is not consistent with proline isomerization. This result suggest that either 115-nitrotyrosyl RNase A is not a good absorbance probe to detect the structural change about Pro-114 or that the amplitude of the expected slow kinetic is too small to be observed.

\subsubsection{Aminotyrosyl RNase A}

Fluorescence spectroscopy is an intrinsically more sensitive technique than absorbance spectroscopy, as the longer excited state lifetime makes it responsive to the most subtle changes in local environment about the fluorophore. As 
discussed above, the absorbance of the nitrotyrosyl group in $\mathrm{C}^{\varepsilon 115-\mathrm{NO}_{2}} \mathrm{RNase} A$ is not very sensitive to changes in the environment about the neighboring Pro-114. Unfortunately, the nitrotyroyl group does not fluoresce to any reasonable extent. However, aminotyrosine is highly fluorescent and the excitation and emission maxima differ from that of tyrosine itself making it an excellent probe for use in protein folding studies. This phenomenon was exploited by Puntambekar in the examination of the folding of aminotyrosyl RNase A.

Puntambekar (1991) has investigated the refolding of the aminated derivatives of RNase $A, C^{\varepsilon 115-N_{2}}$ RNase $A$ and $C^{\varepsilon 115,76-\mathrm{NH}_{2}}$ RNase $A$. The refolding was studied at both $10^{\circ} \mathrm{C}$ in aqueous buffer and $-15^{\circ} \mathrm{C}$ in $35 \%$ methanol at $\mathrm{pH}^{*} 6$. The folding kinetics of both thermal and urea unfolded aminated derivatives were followed with fluorescence spectrophotometry.

Triphasic folding kinetic were observed for both $\mathrm{C}^{\varepsilon 115-\mathrm{NH}_{2}} \mathrm{RNase} A$ and $\mathrm{C}^{\varepsilon 115,76-\mathrm{NH}_{2}} \mathrm{RNase} A$. The results obtained in this study and corresponding NMR data (Biringer, unpublished) strongly suggest that the slowest phase is associated with the isomerization of Pro-114. One characteristic of proline isomerization is the $\mathrm{pH}$ independence of the kinetics. Puntambekar attempted the folding kinetics at $\mathrm{pH}^{*} 3$ but failed because at low $\mathrm{pH}$, the amino group oxidized to corresponding nitro-derivatives of RNase.

In Puntambekar's study, the first and the third kinetic phases for both derivatives are associated with a decrease in fluorescence, but the second phase 


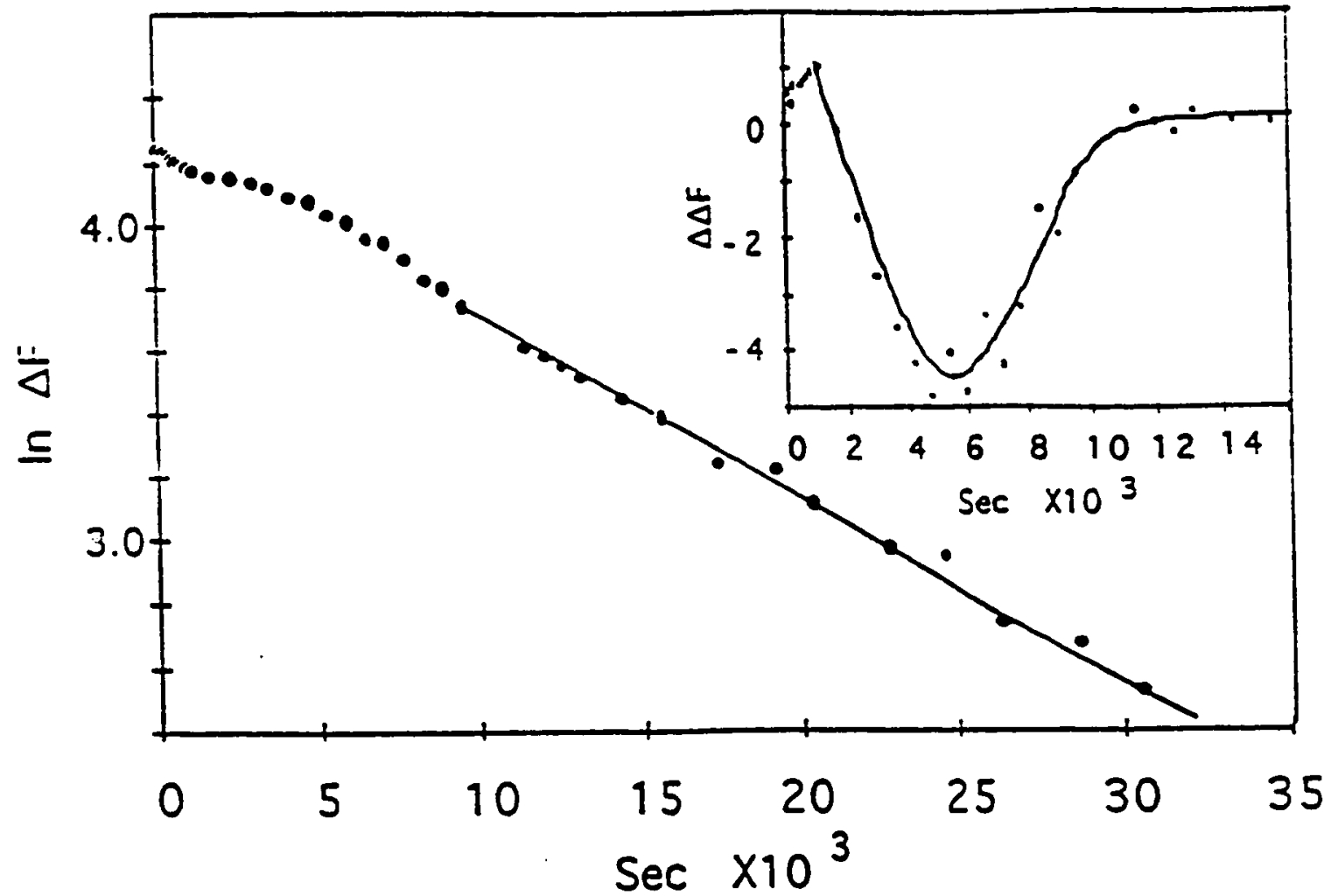

FIGURE 3 : Folding Kinetic for $\mathrm{C}^{\varepsilon 115-\mathrm{NH}_{2}}$ RNase A $(14 \mu \mathrm{M})$ in 35\% Methanol, $\mathrm{pH}^{\star} 6$ and $-15^{\circ} \mathrm{C}$. The data is given as a semilog plot. Stripping of the slowest kinetic phase yields the data given in the inset. Note that the slower phase in the inset shows an increase in fluorescence whereas both other phases show a decrease in fluorescence (taken from Puntambekar, 1991). 
showed an increase in fluorescence (see Figure 3). A decrease in fluorescence was expected for all kinetic phases, as the fluorescence of the derivatives in the native state is considerably lower than that for the unfolded state. Puntambekar proposed that the increase in fluorescence observed for the second kinetic phase could be attributable to the decomposition of an abortive folding intermediate, fluorescence energy transfer between a tyrosine and one or both of the aminotyrosines, or perhaps an event associated with a change in $\mathrm{pK}$ of the aminotyrosine.

\subsection{Goals of the Project}

This project centers around the kinetics of folding of aminated RNases, in particular, the kinetics of folding at both $\mathrm{pH}^{*} 3$ and $\mathrm{pH}^{*} 6$. Earlier studies showed that the folding of aminated $\mathrm{RNases}$ at $\mathrm{pH}^{*} 3$ was complicated by acid catalyzed reoxidation of the aminated RNases to the corresponding nitro-derivatives of RNase A. The first goal of this project involves the examination of various experimental conditions that prevent the oxidation of aminotyrosyl RNases at $\mathrm{pH}^{\star} 3$. The second goal involves the examination of the refolding of $C^{\varepsilon 115-N_{2}}$ RNase $A$ and $C^{\varepsilon 115,76-\mathrm{NH}_{2}}$ RNase $A$ at $\mathrm{pH}^{*} 3$ under the conditions where oxidation does not occur. The third goal involves a re-examination of the $\mathrm{pH}^{*} 6$ folding studies examined previously, in particular, the second kinetic phase. This final goal centers on examining the possibility that fluorescence energy transfer is involved in this process. 


\section{MATERIALS AND METHODS}

\subsection{Materials}

\subsubsection{Reagents}

Bovine pancreatic ribonuclease A (RNase A), N-acetyl-L-tyrosine ethyl ester (ATEE), 3-amino-L-tyrosine, guanidine hydrochloride, tetranitromethane, Sephadex G-200 and ampholytes were purchased from Sigma Chemical Company. Sodium dithionite (Sodium hydrosulfite) was purchased from J. J. Baker Chemical Company. Analytical isoelectric focusing Precotes $\left(\mathrm{pH}^{*} 3-10\right)$ were purchased from Cresent Chemical Company. N-2-hydroxyethylpiperazineN-2-ethanesulfonic acid (HEPES) was purchased from Fisher Biotech.

\subsubsection{Equipment}

Chromatographic experiments were carried out using an ISCO Retriever II Fraction Collector equipped with a UA-5 Absorbance / Fluorescence Detector. Isoelectric focusing experiments were performed with a BioRad Horizontal Electrophoresis apparatus. A Perkin Elmer LS-3 Fluorescence Spectrophotometer and a Hewlett Packard 8452A Diode Array Spectrophotometer were used for fluorescence and absorbance experiments respectively. 


\subsection{Methods}

\subsubsection{Modification and Purification of RNase A}

\subsubsection{Synthesis and Purification of Nitrotyrosyl RNases}

Nitrotyrosyl derivatives of RNase A were prepared as outlined by Biringer and Fink (1988c). A $50 \mathrm{mg}$ sample of RNase A was dissolved in $20 \mathrm{~mL}$ of borate buffer $(0.1 \mathrm{M})$ at $\mathrm{pH}^{*} 8$. A 30 fold molar excess of $8 \%(\mathrm{v} / \mathrm{v})$ tetranitromethane (TNM) solution in $90 \%(\mathrm{v} / \mathrm{v})$ ethanol was added. The reaction was carried out under the hood for 20 minutes with constant stirring at room temperature. In order to quench the reaction, the product was applied to G-25 column with $0.1 \mathrm{M}$ ammonium hydroxide. Unreacted TNM was removed in this process.

In addition to desired products, dimers are also formed in the reaction because the reaction proceeds through radical mechanism. The dimers were removed with size exclusion chromatography using G-75 $(2.5 \times 20 \mathrm{~cm})$ with $0.15 \mathrm{M}$ phosphate buffer at $\mathrm{pH} 6.5$ as the eluent. The monomeric fractions were collected, dialyzed, and lyophylized.

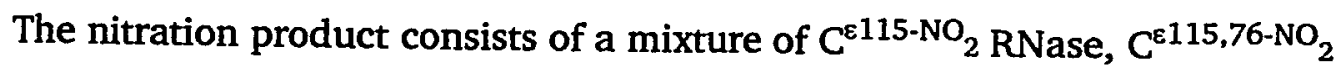
RNase, $\mathrm{C}^{\varepsilon 115,76,73-\mathrm{NO}_{2}}$ RNase and unreacted RNase. These proteins are readily separated by IEF, as their isoelectric points (pI) differ by at least 0.2 units. For this purpose, a granular resin bed buffered with ampholytes $\left(\mathrm{pH}^{*} 8-10.5\right)$ was prepared. A solution of $5.6 \%(\mathrm{w} / \mathrm{v})$ ampholytes was prepared by dissolving 14 $\mathrm{mL}$ of concentrated ampholytes in $110 \mathrm{~mL}$ of deionized distilled water. Next, $13 \mathrm{~g}$ 
Sephadex G-200 was added and swirled until all the resin was wet. Nitrogen gas was blown into the container to remove $\mathrm{CO}_{2}$ and then sealed and placed in the refrigerator overnight to swell. The swelled resin was then transferred in to a preparative IEF chamber $(0.4 \times 10 \times 20 \mathrm{~cm})$. Stacks of electrode wicks that were soaked with $0.1 \mathrm{M} \mathrm{NaOH}$ were placed to one side (the cathode) and the others soaked with 0.1 M HEPES (N-2-hydroxyethylpiperazine- N-2-ethanesulfonic acid)placed on the other side (the anode). The plate was placed in the electrophoresisunit which was precooled to $2^{\circ} \mathrm{C}$. Pre-electrophoresis was carried out for 45 minutes at 10 Watts constant power. All IEF was done in a nitrogen gas atmosphere.

Immediately after pre-electrophoresis, the nitrated protein was dissolved in a minimum amount of $5.6 \%(\mathrm{w} / \mathrm{v})$ ampholytes and applied across the center of the gel in thin strip. The gel was electrophoresed at 30-40 Watts constant power until three well separated yellow bands were appeared ( $4-8$ hours). The individual bands were scooped out and separated from the resin by washing the \resin with deionized distilled water via vacuum filtration in a scintered glass funnel. The products were dialyzed and lyophilized. The purity of the products was checked with analytical IEF as described below.

Precotes (ready to use acrylamide gels) were used for analytical IEF. A 2.5 to $5 \mu \mathrm{L}$ of aliquot of a $5 \mathrm{mg} / \mathrm{mL}$ solution of each derivative as well as marker proteins and unmodified RNase A were individually applied to the gel through applicator strips. The gel was electrophoresed for 2 hours at $2^{\circ} \mathrm{C}$ at 4 Watts constant power. The precotes were fixed with $20 \%$ trichloroacetic acid and 
stained with coomassie brilliant blue in universal solvent (40\% methanol, $50 \%$ water, $10 \%$ acetic acid).

\subsubsection{Synthesis and Purification of Aminotyrosyl RNases}

Aminotyrosyl derivatives were prepared by the reduction of the

corresponding nitro-derivative with dithionite. The reduction of $\mathrm{C}^{\varepsilon 115-\mathrm{NO}_{2}} \mathrm{RNase}$ and $C^{8115,76-\mathrm{NO}_{2}}$ RNase $A$ with dithionite ion gives $\mathrm{C}^{\varepsilon 115-\mathrm{NH}_{2}}$ RNase $\mathrm{A}$ and $\mathrm{C}^{\varepsilon 115,76-\mathrm{NH}_{2}} \mathrm{RNase} A$ respectively. The individual nitro-derivatives were dissolved to final concentration of $10 \mathrm{mg} / \mathrm{mL}$ in $0.05 \mathrm{M}$ tris buffer at $\mathrm{pH} * 8$. A 75 molar excess of dithionite was dissolved in an equal volume of the tris buffer and then added to the protein solution. After 5 minutes of reaction with constant stirring, the product was applied to a G-25 column $(2.5 \times 20 \mathrm{~cm})$ and eluted with deionized distilled water. This step removes the unreacted dithionite and low molecular weight by-products.

Residual unreduced protein was removed by chromatofocusing. A PBE-118 column $\left(1 \times 20 \mathrm{~cm}\right.$ ) was equilibrated with $0.025 \mathrm{M}$ triethyl amine at $\mathrm{pH}^{*} 11$. The protein was dissolved in $1 \mathrm{~mL}$ diluted ampholytes $(1: 45)$ at $\mathrm{pH}^{*} 8$. The solution was then applied to the column and eluted with the diluted ampholytes. The major peak was collected, dialyzed, and then lyophilized. The purity was checked with analytical IEF as described above. 


\subsubsection{Deoxygenation Protocol}

Earlier studies show that the refolding of the aminotyrosyl RNase at $\mathrm{pH}^{*} 3$ is complicated by the acid catalyzed reoxidation of the aminotyrosines by dissolved oxygen gas. In order to overcome this problem, two deoxygenation protocols were examined: degassing and nitrogen purging.

For the degassing experiment, stock protein solution was prepared by dissolving 0.2-0.5 $\mathrm{mg}$ of $\mathrm{C}^{\varepsilon 115-\mathrm{NH}_{2}}$ RNase $\mathrm{A}$ in the refolding buffer (35\% methanol, $\mathrm{pH}^{*} 3$, and $0.033 \mathrm{M}$ formate) to final concentration of $10 \mathrm{mg} / \mathrm{mL}$. Both the protein stock solution in a vial and $1 \mathrm{~mL}$ of the refolding buffer in a fluorometer cell were placed in a bell jar chamber and vacuum was pulled with house vacuum for 15 minutes. Following degassing, the vial containing the protein was sealed with parafilm and the fluorometer cell containing the refolding buffer was closed tightly and then placed in a temperature equilibrated $\left(-15^{\circ} \mathrm{C}\right)$ fluorometer chamber. A $60 \mu \mathrm{L}$ aliquot of stock protein solution was taken up in a gas tight syringe and then incubated in dry bath incubator for 10 minute at $70{ }^{\circ} \mathrm{C}$. The heat unfolded protein was injected into the refolding buffer, stirred for 20-30s, sealed, and allowed to fold to completion (7-8 hours). The fluorometer chamber was constantly purged with dry nitrogen gas to avoid the buildup of ice. The cell containing refolded protein was taken out of the refolding chamber and allowed to warm to room temperature and absorption spectrum was taken. Next, $25 \mu \mathrm{L}$ of $1 \mathrm{M} \mathrm{NaOH}$ was added to the protein solution to raise the $\mathrm{pH}$ above 8 and then the absorption spectrum was scanned again. Under basic conditions, 
nitrotyrosine gives well defined peak at $428 \mathrm{~nm}$ (Biringer, unpublished results).

The second deoxygenation protocol involved nitrogen purging. The protein stock solution and refolding buffer were prepared as noted above and nitrogen gas was bubbled through the solutions for 15 minutes. The nitrogen gas was passed through 35\% methanol prior to entering the solution to prevent the evaporation of the solution. The rest of the procedure is the same as the degassing protocol. Both procedures were applied to both aminotyrosyl derivatives.

\subsubsection{Refolding of Aminotyrosyl RNases}

The refolding kinetics of $C^{\varepsilon 115-\mathrm{NH}_{2}} \mathrm{RNase} A$ and $C^{\varepsilon 115,76-\mathrm{NH}_{2}} \mathrm{RNase} A$ were examined at $\mathrm{pH}^{*} 3\left(0.033 \mathrm{M}\right.$ formate) and $-15^{\circ} \mathrm{C}$. The experimental procedure was the same as outlined above and the degassing with vacuum protocol was used to remove oxygen. The refolding was monitored by the aminotyrosine

fluorescence: $305 \mathrm{~nm}$ excitation and 405 emission wavelengths for $\mathrm{C}^{\varepsilon 115-\mathrm{NH}_{2}}$ RNase $A$, and $305 \mathrm{~nm}$ excitation and $368 \mathrm{~nm}$ emission wavelengths for $\mathrm{C}^{\varepsilon 115,76-\mathrm{NH}_{2}} \mathrm{RNase} \mathrm{A}$. Absorbance spectra were taken after the completion of folding so that the amplitudes obtained from the folding kinetics could be standardized to one another. In order to check for the occurrence of any appreciable oxidation, the $\mathrm{pH}$ of the solution was raised to 8 and the absorbance was scanned. 


\subsubsection{Guanidine Denaturation of Amino RNases}

In order to quantitate the amplitudes obtained from the folding kinetics, the guanidine hydrochloride denaturation of aminated RNases at $-15{ }^{\circ} \mathrm{C}$ in $35 \%$ ( $v / v$ ) methanol was examined at $\mathrm{pH}^{*}$ 3. A $6.316 \mathrm{M}$ guanidine hydrochloride solution was prepared in $35 \%(\mathrm{v} / \mathrm{v})$ methanol, $0.033 \mathrm{M}$ formate and $\mathrm{pH}^{*} 3$. The protein stock solution was prepared by dissolving a $10 \mathrm{mg}$ sample of aminated RNase A in $2 \mathrm{~mL}$ buffer ( $35 \%(\mathrm{v} / \mathrm{v})$ methanol, 0.033 formate at $\mathrm{pH}^{*} 3$ ). A dilution series ranging from $0 \mathrm{M}$ to $6 \mathrm{M}$ guanidine hydrochloride was prepared by mixing specific volumes of the $6.316 \mathrm{M}$ gaunidine hydrochloride solution and the $35 \%$ methanol buffer. Experimental solutions were prepared by adding $100 \mu \mathrm{L}$ of protein stock solution to $1900 \mu \mathrm{L}$ of each denaturant concentration. The fluorescence of the solutions was measured at $-15^{\circ} \mathrm{C}$. Also, for each guanidine hydrochloride concentration, a blank ( $100 \mu \mathrm{L}$ of $35 \%$ methanol was added instead of the protein) was measured.

\subsubsection{Fluorescence Energy Transfer}

In order to examine the possibility that the unique fluorescence increase observed in folding kinetics at $\mathrm{pH}^{*} 6$ involves fluorescence energy transfer, two sets of experiments were performed. One set involved the use of model compounds. The second involved obtaining both excitation and emission spectra during the folding of both $\mathrm{C}^{\varepsilon 115-\mathrm{NH}_{2}}$ RNase $\mathrm{A}$ and $\mathrm{C}^{\mathrm{E} 115,76-\mathrm{NH}_{2}} \mathrm{RNase} \mathrm{A}$.

\subsubsection{Model Compounds}


A series of solutions were prepared in $35 \%(\mathrm{v} / \mathrm{v})$ methanol, 0.033 acetate buffer and at $\mathrm{pH}^{*} 6$. The solutions were all $40 \mu \mathrm{M}$ in aminotyrosine and varied in concentration of acetyltyrosine ethyl ester from $25 \mu \mathrm{M}$ to $100 \mu \mathrm{M}$. The fluorescence emission of each solution was scanned with an excitation at $288 \mathrm{~nm}$. Next, the emission wavelength was set to the emission maximum of $350 \mathrm{~nm}$ and the excitation spectrum was scanned. The experiments were carried out at $-15{ }^{\circ} \mathrm{C}$.

\subsubsection{Aminated RNases}

The refolding of both $\mathrm{C}^{\mathrm{\varepsilon} 115-\mathrm{NH}_{2}} \mathrm{RNase} \mathrm{A}$ and $\mathrm{C}^{\varepsilon 115,76-\mathrm{NH}_{2}}$ RNase $\mathrm{A}$ were initiated at $\mathrm{pH}^{*} 6$ using the method described above for the refolding at $\mathrm{pH}^{*} 3$ with the exception that the refolding solution was buffered with acetate at $\mathrm{pH}^{*} 6$ instead of formate at $\mathrm{pH}^{*} 3$. At the various time intervals, the excitation and emission spectra were scanned. The emission wavelengths were set to $390 \mathrm{~nm}$ and $350 \mathrm{~nm}$ for scanning the excitation spectra of $C^{\varepsilon 115-\mathrm{NH}_{2}} \mathrm{RNase} A$ and $\mathrm{C}^{\varepsilon 115,76-\mathrm{NH}_{2}}$ RNase A respectively. When scanning the emission spectra, the excitation wavelengths were set to $298 \mathrm{~nm}$ and $288 \mathrm{~nm}$ for $\mathrm{C}^{\varepsilon 115-\mathrm{NH}_{2}} \mathrm{RNase} \mathrm{A}$ and $\mathrm{C}^{\varepsilon 115,76-\mathrm{NH}_{2}} \mathrm{RNase} A$ respectively. In addition, the excitation and emission spectra for each of the native and denatured (6 M guanidine hydrochloride, $35 \%$ ( $\mathrm{v} / \mathrm{v})$ methanol, $0.033 \mathrm{M}$ acetate at $\mathrm{pH}^{\star}$ 6) proteins were scanned. These were measured to serve as a standard for the unfolded state. 


\section{RESULTS AND DISCUSSION}

\subsection{Deoxygenation}

The folding of the aminated derivatives of $\mathrm{RNase} A$ at $\mathrm{pH}^{*} 3,-15^{\circ} \mathrm{C}$, and $35 \%(v / v)$ methanol in an earlier study (Puntambekar, 1991) was not successful. The aminated derivatives tended to oxidize to corresponding nitrated derivatives of RNase A under these experimental conditions. The kinetic data obtained in this situation represents a combination of folding and oxidation reactions. On the other hand, such a problem did not occur in the refolding experiment at $\mathrm{pH}^{*} 6$ under an otherwise identical set of conditions. The author concluded that the oxidation is acid catalyzed.

The presence of nitrotyrosine in a sample is readily determined by

examining the absorption spectrum. The absorption spectrum of $\mathrm{C}^{\varepsilon 115-\mathrm{NO}_{2}} \mathrm{RNase}$ A at $\mathrm{pH}^{*} 8$ is shown in Figure 4. The peak near $428 \mathrm{~nm}$ is characteristic for nitrated $\mathrm{RNase}$ at $\mathrm{pH}^{\star} \geq 8$. Checking the absorbance spectra at this $\mathrm{pH}$ after the refolding experiment is complete will show if any appreciable oxidation has occurred.

Post-folding absorption spectra were taken for both $\mathrm{C}^{\varepsilon 115-\mathrm{NH}_{2}} \mathrm{RNase} A$ and $\mathrm{C}^{\varepsilon 115,76-\mathrm{NH}_{2}}$ RNase $\mathrm{A}$ that were treated by both the deoxygenation (Figures 5 and 6) and degassing (Figures 7 and 8) methods. The absence of a $428 \mathrm{~nm}$ absorbance band clearly indicates that both methods prevent the oxidation of 


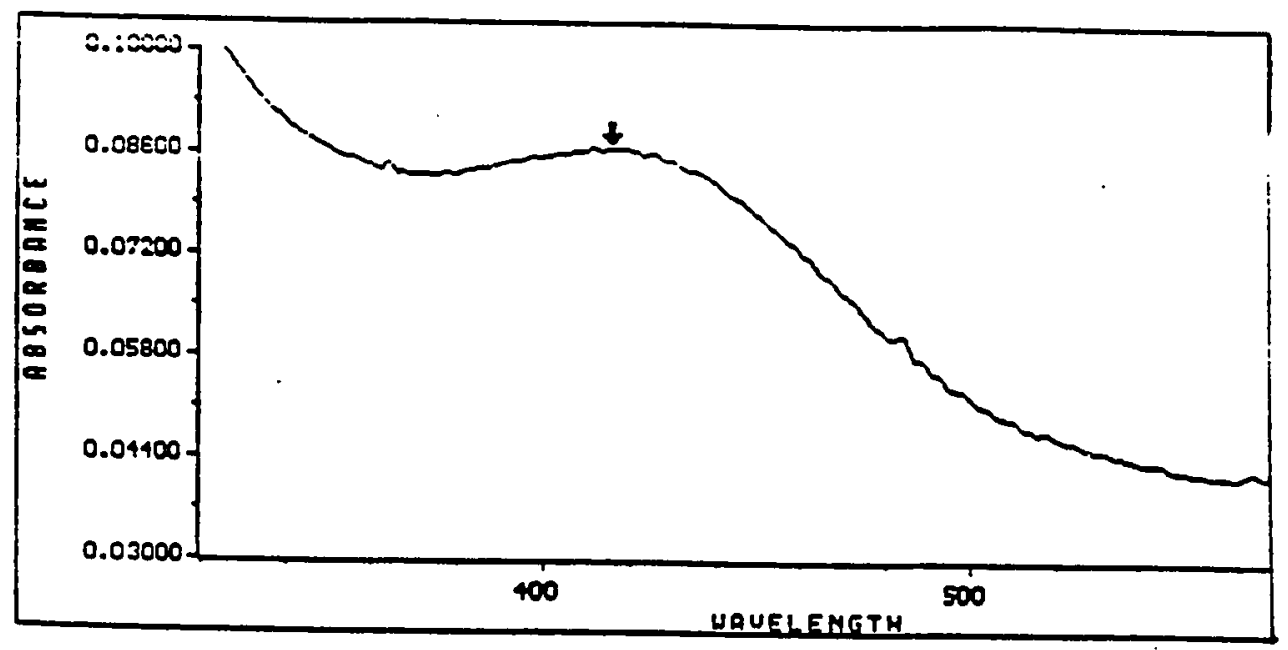

FIGURE 4 : Absorption spectrum of $\mathrm{C}^{\mathrm{E} 115-\mathrm{NO}_{2}}$ RNase $\mathrm{A}(14 \mu \mathrm{M})$, in $35 \%$ methanol at $\mathrm{pH}^{\star} 8$. Arrow indicates $428 \mathrm{~nm}$. 
aminotyrosine to nitrotyrosine.

It is important to note that both methods should applied for a minimum period of time in order to avoid evaporation. The vacuum degassing procedure was chosen for subsequent folding experiments because it is the easier of the two methods.

\subsection{Guanidine Hydrochloride Unfolding of $\mathrm{C}^{\mathrm{E115}-\mathrm{NH}_{2}}$ RNase $A$ and}

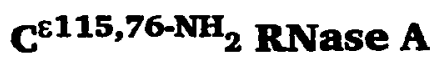

Normally, the folding amplitudes obtained from kinetics experiments are quantitated by comparing the observed amplitudes with the amplitude difference between native and unfolded protein obtained from equilibrium denaturation experiments. Such data can be obtained from both thermal and chemical denaturation experiments.

Both $\mathrm{C}^{\varepsilon 115-\mathrm{NH}_{2}} \mathrm{RNase} \mathrm{A}$ and $\mathrm{C}^{\varepsilon 115,76-\mathrm{NH}_{2}}$ RNase $\mathrm{A}$ were dissolved in a series of guanidine hydrochloride solutions in $35 \%(\mathrm{v} / \mathrm{v})$ methanol $(0.033 \mathrm{M}$ formate) at $\mathrm{pH}^{*}$. The fluorescence at $-15^{\circ} \mathrm{C}$ as a function of guanidine concentration is given in Figure 9. Surprisingly, no appreciable increase in fluorescence was observed for either amino-derivative. At $\mathrm{pH}^{*} 6$, a fluorescence increase was observed for both derivatives when they were unfolded with $6 \mathrm{M}$ guanidine hydrochloride under an otherwise identical set of conditions (Puntambekar, 1991). Evidently, an effective quencher was present in the 


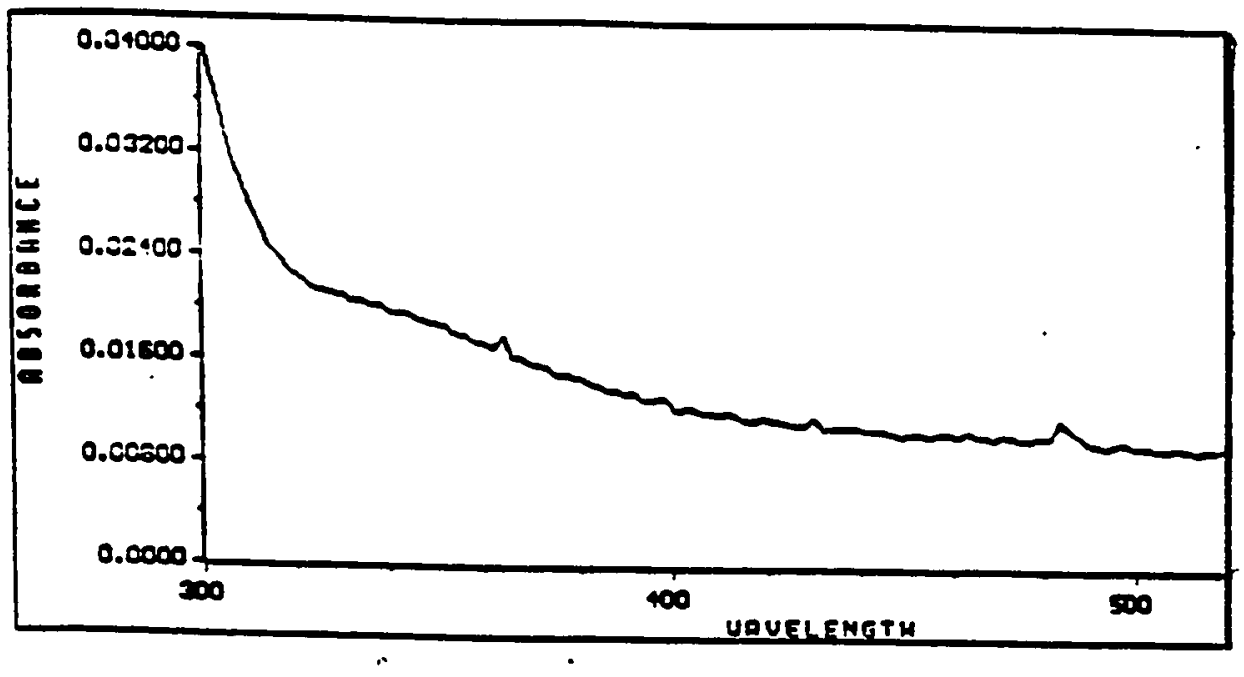

FIGURE 5 : Absorption spectrum of $C^{115 \cdot \mathrm{NH}_{2}}$ RNase $A(14 \mu \mathrm{M})$, in $35 \%$ methanol at $\mathrm{pH}^{\star} 8$ after degassing and subsequent folding. The protein stock solution and folding buffer were degassed with house vacuum for 15 minutes. 


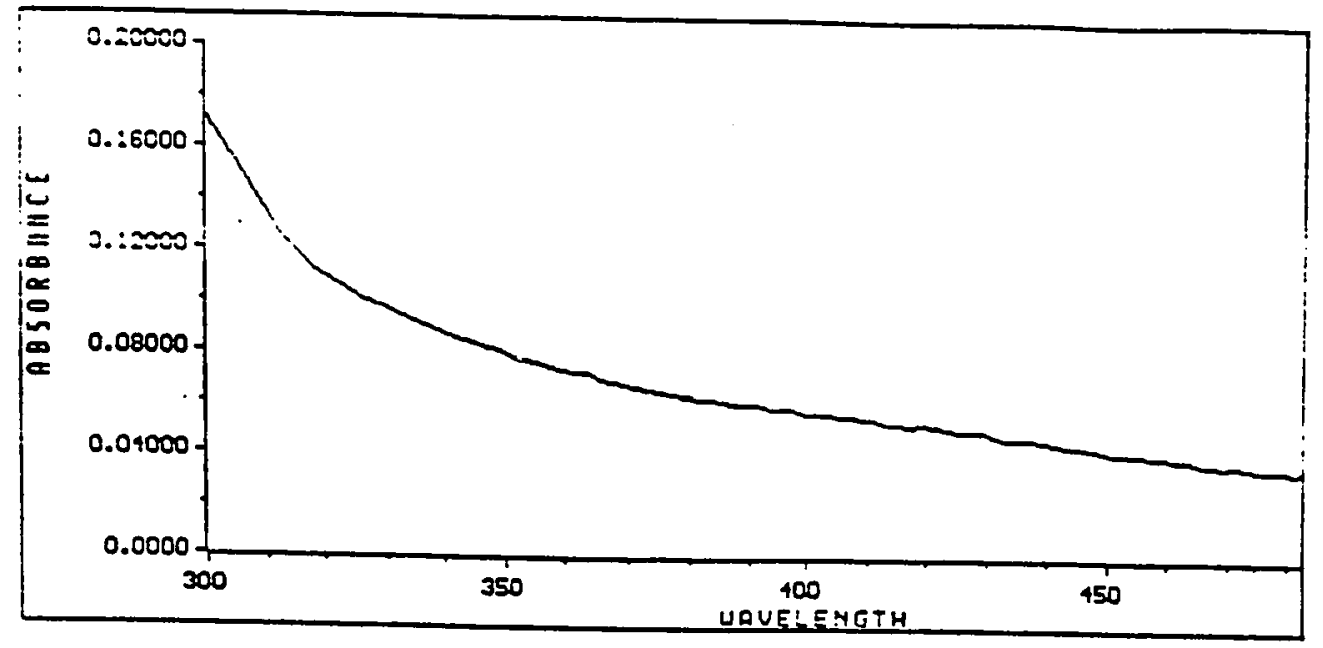

FIGURE 6 : Absorption spectrum of $\mathrm{C}^{\varepsilon 115,76-\mathrm{NH}_{2}}$ RNase A $(14 \mu \mathrm{M})$, in $35 \%$ methanol at $\mathrm{pH}^{\star} 8$ after degassing and subsequent folding. The protein stock solution and folding buffer were degassed with house vacuum for 15 minutes. 


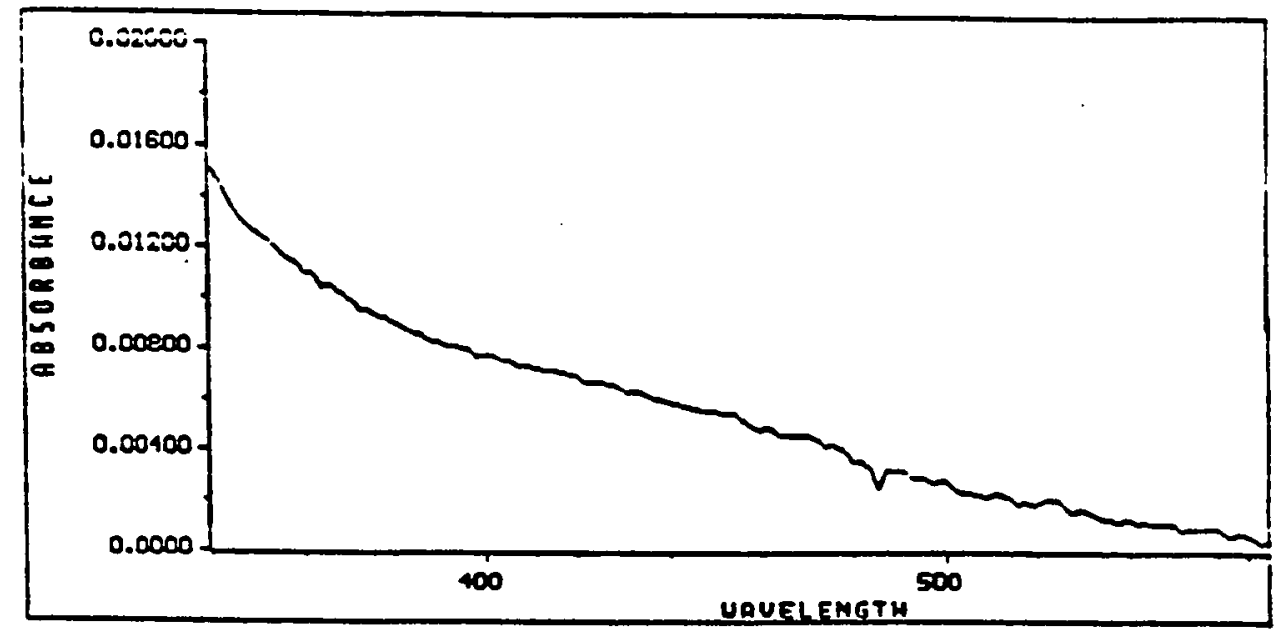

FIGURE 7 : Absorption spectrum of $\mathrm{C}^{\varepsilon 115-\mathrm{NH}_{2}}$ RNase $\mathrm{A}(14 \mu \mathrm{M})$ in $35 \%$ methanol at $\mathrm{pH}^{\star} 8$. The protein stock solution and folding buffer were purged with nitrogen gas for 15 minutes. 


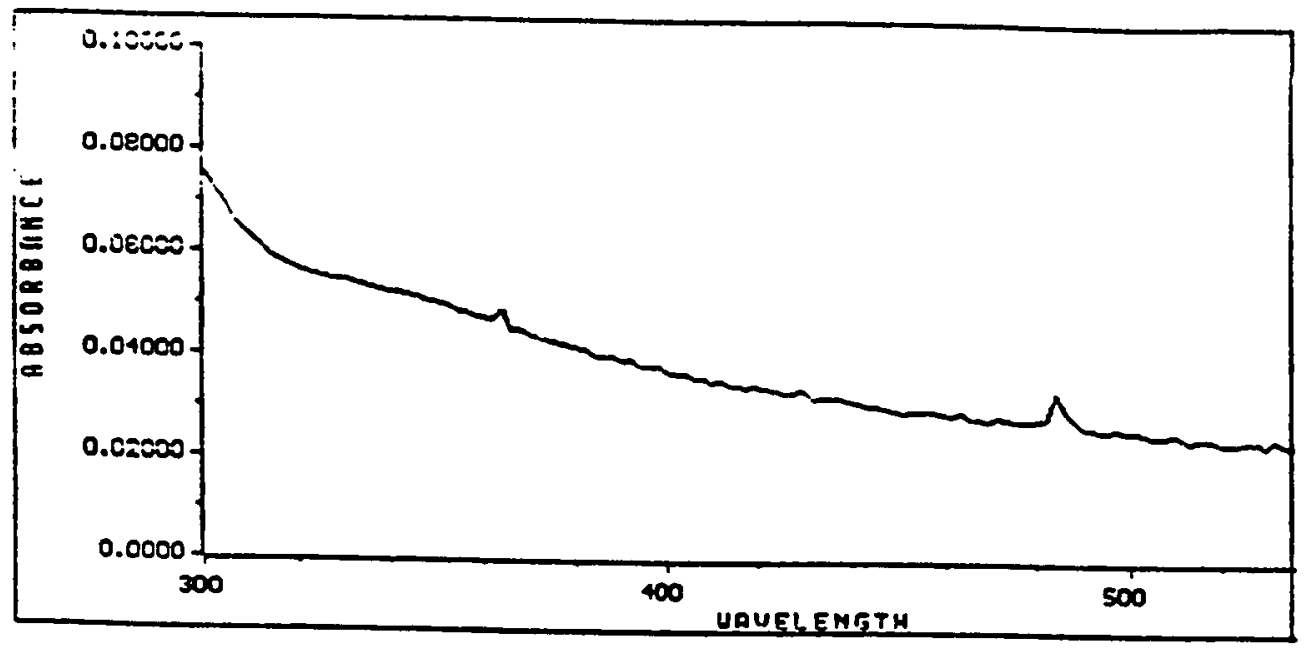

FIGURE 8 : Absorption Spectrum of $C^{\varepsilon 115,76-\mathrm{NH}_{2}}$ RNase A $(14 \mu \mathrm{M})$ in $35 \%$ methanol at $\mathrm{pH}^{\star} 8$. The protein stock solution and folding buffer were purged with nitrogen gas for 15 minutes. 


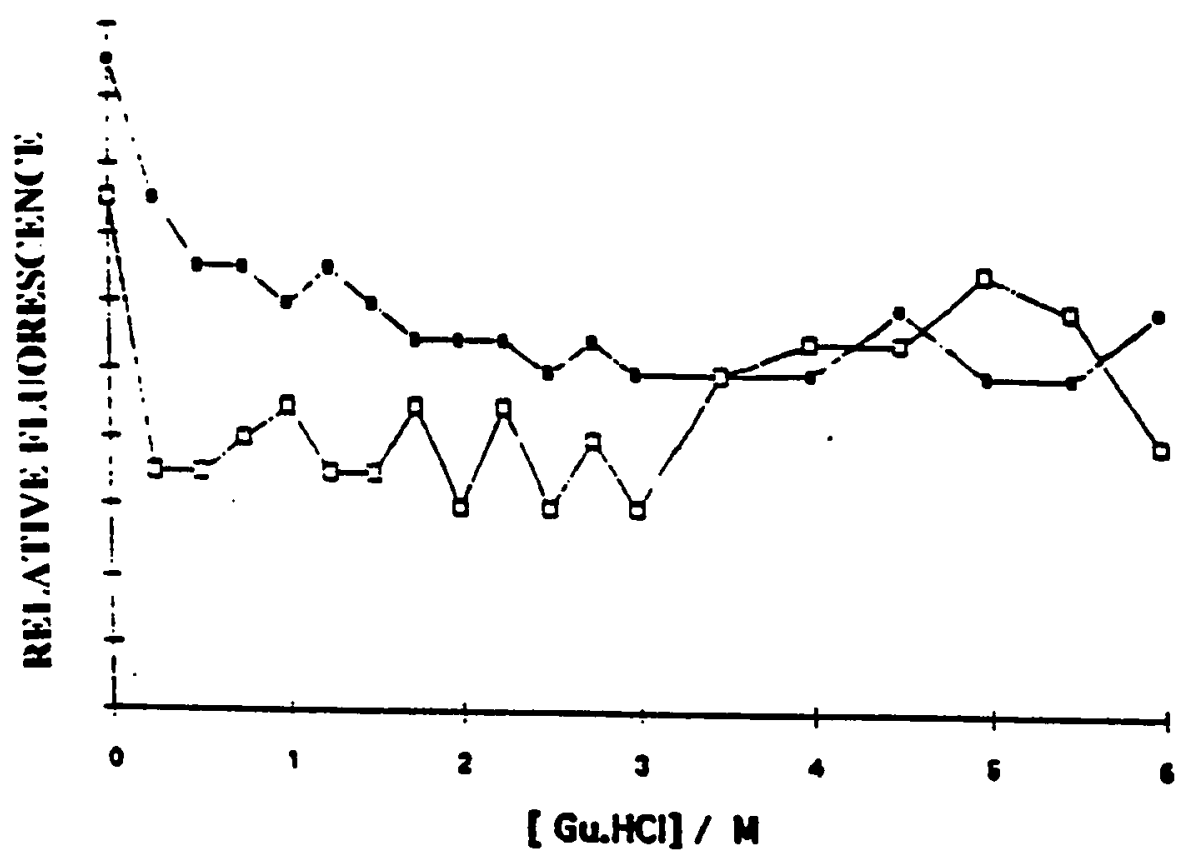

FIGURE 9 : Guanidine hydrochloride unfolding of aminated RNases $(14 \mu \mathrm{M})$ in $35 \%$ methanol, $\mathrm{pH}^{\star} 3$, and $-15^{\circ} \mathrm{C}$. Filled squares represent the data for $\mathrm{C}^{\mathrm{E} 115-\mathrm{NH}_{2}}$ RNase A ( $305 \mathrm{~nm}$ excitation and $405 \mathrm{~nm}$ emission). Open squares represent the data for $C^{\varepsilon 115,76-\mathrm{NH}_{2}}$ RNase $A(305 \mathrm{~nm}$ excitation and $368 \mathrm{~nm}$ emission). 
solution. Since it is known that formate ion does not quench the aminotyrosine fluorescence, the denaturant must play a role in quenching the fluorescence in some fashion. In all cases, the fluorescence of the native protein is higher than that of the proteins in guanidine hydrochloride solutions. Above $0.5 \mathrm{M}$ guanidine hydrochloride the fluorescence of $\mathrm{C}^{\varepsilon 115-\mathrm{NH}_{2}} \mathrm{RNase} \mathrm{A}$ is independent of the denaturant concentration. The fluorescence of $\mathrm{C}^{\mathrm{E115}, 76-\mathrm{NH}_{2}} \mathrm{RNase} A$ decreases at low concentration of denaturant and stays constant up to a guanidine hydrochloride concentration of $3 \mathrm{M}$. From $3 \mathrm{M}$ to $5 \mathrm{M}$ denaturant concentration, the intensity increases slightly with increasing denaturant concentration, but never reaches the fluorescence of the native protein.

The denaturation of amino RNases was tested with $8 \mathrm{M}$ urea at $\mathrm{pH}^{*} 3$ and $-15^{\circ} \mathrm{C}$. No appreciable fluorescence increase was observed with this denaturant as well. In order to examine this further, a control experiment was performed to see if these denaturants are capable of quenching aminotyrosine. The addition of $100 \mu \mathrm{L}$ of $1 \mathrm{mM}$ 3-amino-L-tyrosine to $1900 \mu \mathrm{L}$ of $3 \mathrm{M}$ of guanidine hydrochloride solution reduces the emission amplitude at $390 \mathrm{~nm}$. This confirms that the denaturants themselves are responsible for the quenching.

The quenching abilities of guanidine hydrochloride and urea have not been observed previously and deserve further examination. The fact that quenching does occur make it impossible to obtain maximal expected amplitude. Thus, amplitudes from the $\mathrm{pH}^{*} 3$ kinetics data cannot be standardized at this time. 


\subsection{Folding of $C^{\varepsilon 115-N_{2}}$ RNase $A$ and $C^{\varepsilon 115,76-N_{2}}$ RNase $A$}

It is known that unfolded RNase A consists of both slow folding and fast folding species (Garel and Baldwin, 1975). There are two known paths followed by the slow folding species (Schmid and Blaschek, 1981); the major slow folding path is followed by $50 \%$ of these species and the minor slow folding represents $30 \%$ of these species. The folding is characterized by multiphasic kinetics and intermediates have been detected and characterized for both minor and major slow folding pathways. The involvement of Pro-93 in the minor pathway is also well established. The involvement of Pro-114 in particular pathway has yet to be established.

The amino-derivatives of RNase A have emission spectra that are well resolved from that of the unmodified protein. The emission spectra for these derivatives are shown in Figure 10. The emission maximum is at $405 \mathrm{~nm}$ for $\mathrm{C}^{\varepsilon 115-\mathrm{NH}_{2}} \mathrm{RNase} A$ and $368 \mathrm{~nm}$ for $\mathrm{C}^{\varepsilon 115,76-\mathrm{NH}_{2}}$ RNase A. The 115-aminotyrosine fluorescence should reflect the configurational changes of Pro-114, as it is adjacent to this residue. However, the results of Biringer and Fink (1988b) on the folding of 115-nitrotyrosyl $\mathrm{RNase} \mathrm{A}$ at $\mathrm{pH}^{*} 3$ and 6 in methanol cryosolvent showed no sensitivity of $\mathrm{C}^{\varepsilon 115-\mathrm{NO}_{2}} \mathrm{RNase} A$ absorbance to Pro-114 isomerization. Puntambekar (1991) on the other hand, suggested that the slow phase in the folding of aminotyrosyl $\mathrm{RNase} \mathrm{A}$ at $\mathrm{pH}^{*} 6$ was associated to Pro-114 isomerization. 


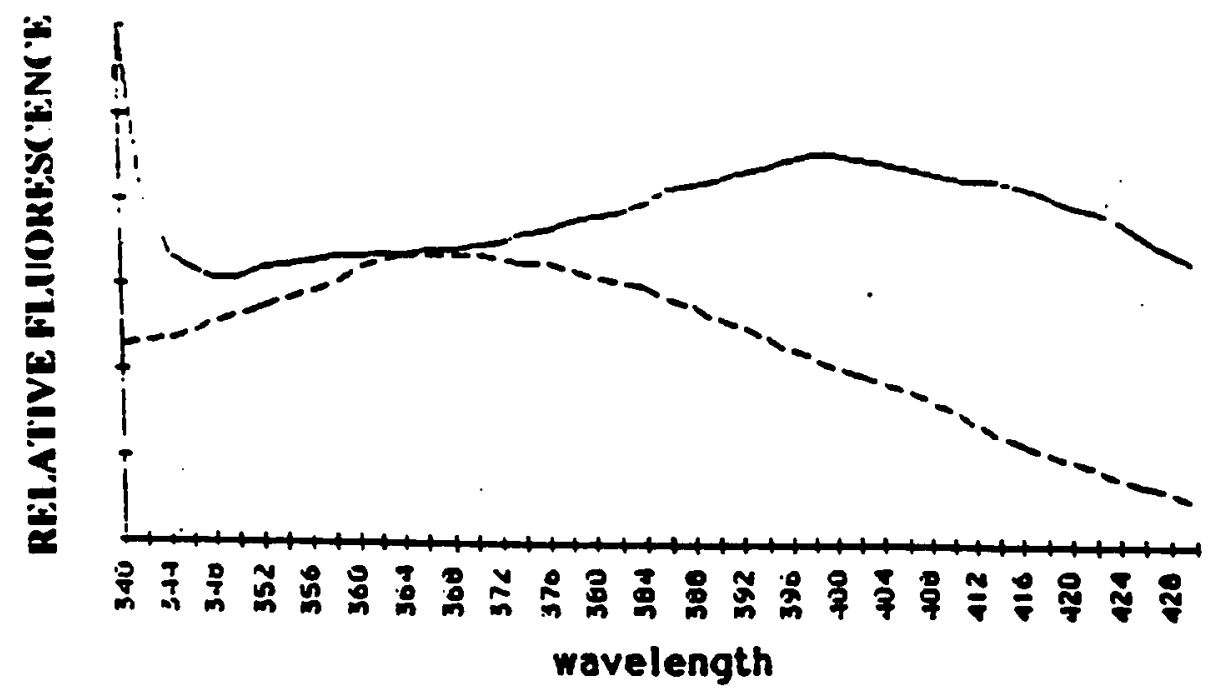

FIGURE 10 : The fluorescence emission spectra (305 nm excitation) of $\mathrm{C}^{\varepsilon 115-\mathrm{NH}_{2}}$ RNase $A(14 \mu \mathrm{M})$ and $C^{\varepsilon 115,76-\mathrm{NH}_{2}}$ RNase $\mathrm{A}(14 \mu \mathrm{M})$ in $35 \%$ Methanol, $\mathrm{pH}^{\star} 3$ and

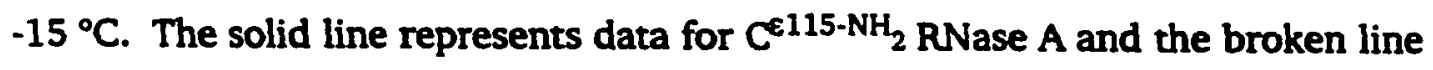
represents data for $C^{\varepsilon 115.76-\mathrm{NH}_{2}} \mathrm{RNase} A$. 
In this study, the folding of $C^{\varepsilon 115-\mathrm{NH}_{2}}$ RNase $A$ and $C^{\varepsilon 115,76-\mathrm{NH}_{2}}$ RNase $A$ was investigated at $\mathrm{pH}^{*} 3$ in $35 \%$ methanol $(\mathrm{v} / \mathrm{v}),-15^{\circ} \mathrm{C}$ in order to examine the dependence of the kinetics on $\mathrm{pH}$. The kinetics of folding for both $\mathrm{C}^{\varepsilon 115-\mathrm{NH}_{2}}$ RNase $A$ and $C^{\varepsilon 115,76-\mathrm{NH}_{2}}$ RNase $A$ were biphasic. The time dependent changes in the fluorescence emission for these derivatives are shown in Figures 11 and 12. The data was analyzed utilizing semilog plots and standard stripping methods. Linear regression analysis of the semilog plots was carried out using Excel ${ }^{\mathrm{TM}}$ (Microsoft). The data was also analyzed by a non linear least squares fit of the raw data with NFIT ${ }^{\mathrm{TM}}$ (Island Products). In all cases the rate constants obtained from both methods are within experimental error.

Both of the analysis techniques require that the fluorescence emission at the end of the folding process be known with reasonable accuracy. In long term kinetics, it is difficult to determine when the process is complete. In order to insure that the data obtained using the methods mentioned above were accurate, the slow phase kinetics were also examined with Guggenheim method (Guggenheim, 1926). The Guggenheim method allows one to calculate a rate constant without having an amplitude at infinite time. It was found that the slowest rates calculated by Guggenheim and by the other methods are in reasonable agreement.

Table 2 gives the rate constants and amplitudes along with those for folding at $\mathrm{pH}^{*} 6$ (Puntambekar, 1991). It is important to note here that the 

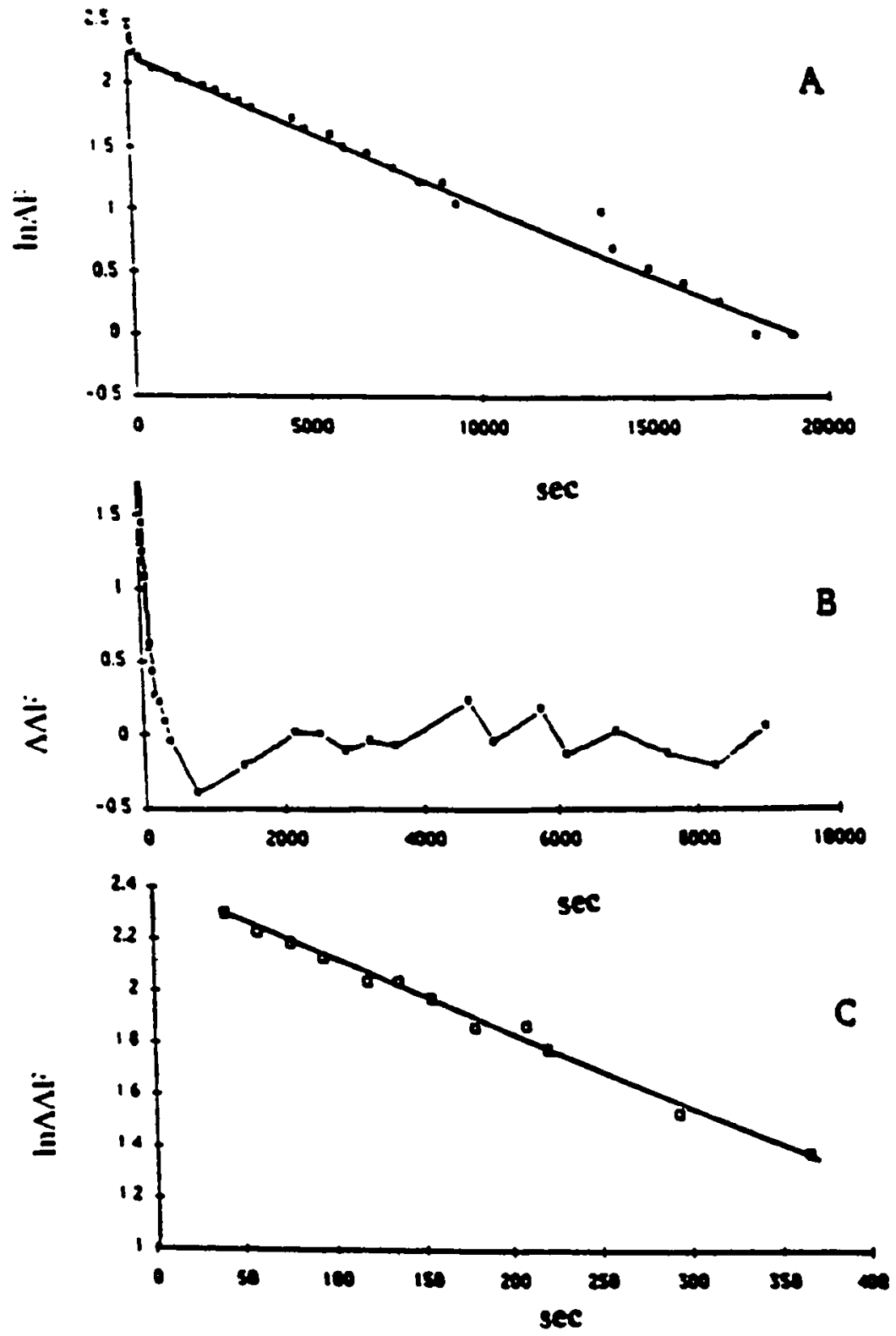

FIGURE 11: Time dependent changes in the refolding of $\mathrm{C}^{\varepsilon 115 \cdot \mathrm{NH}_{2}} \mathrm{RNase} A$ (14 $\mu \mathrm{M}$ ) in $35 \%$ methanol, $\mathrm{pH}^{\star} 3$, and $-15^{\circ} \mathrm{C}$. (A) Semilog plot of entire data set; (B) Raw data after slowest phase was stripped; (C) semilog plot of the data given in B. 


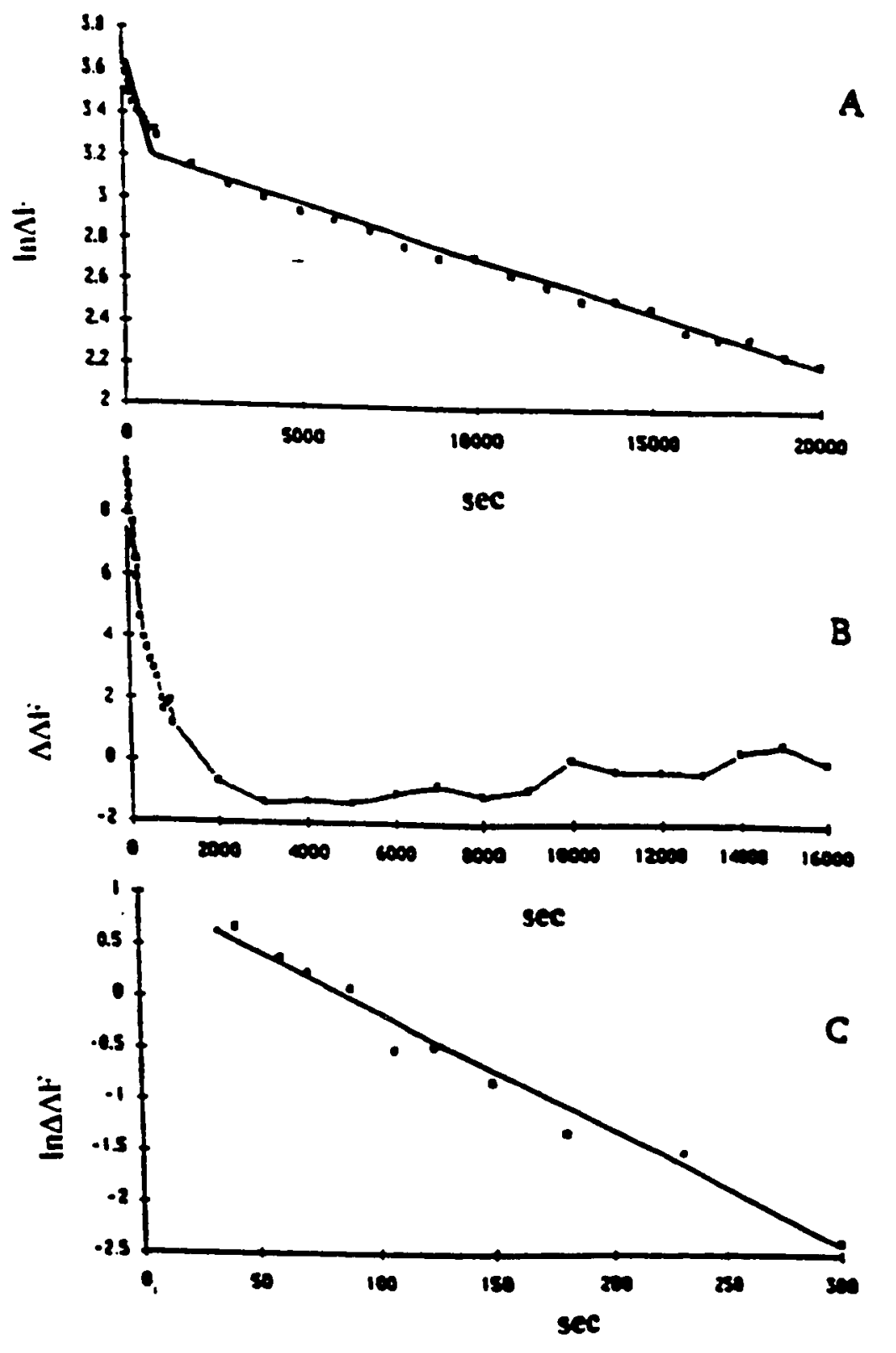

FIGURE 12: Time dependent changes in the refolding of $\mathrm{C}^{£ 115.76-\mathrm{NH}_{2}} \mathrm{RNase} A$ $(14 \mu \mathrm{M})$ in $35 \%$ methanol, $\mathrm{pH}^{\star} 3$, and $-15^{\circ} \mathrm{C}$. (A) Semilog plot of entire data set; (B) Raw data after slowest phase was stripped; (C) semilog plot of the data given in $B$. 
TABLE 2: Folding Kinetics of $C^{\varepsilon 115-\mathrm{NH}_{2}}$ RNase $A$ and $C^{\varepsilon 115,76-\mathrm{NH}_{2}}$ RNase $A$ in $35 \%(\mathrm{v} / \mathrm{v})$ Methanol, $-15^{\circ} \mathrm{C}, 0.033 \mathrm{M}$ Formate.

\begin{tabular}{|c|c|c|c|c|}
\hline & \multicolumn{3}{|c|}{$p H^{*} 6^{1}$} & \multirow[b]{2}{*}{$\begin{array}{l}\text { k3 (AMP) } \\
\times 10^{5}\end{array}$} \\
\hline & $\begin{array}{l}k_{1}(A M P) \\
X 10^{3}\end{array}$ & & $\begin{array}{l}k_{2} \text { (AMP) } \\
X 10^{4}\end{array}$ & \\
\hline$C^{\varepsilon 115-N_{2}}$ RNase A & $1.4(15)$ & & $5.3(-23)$ & 6.1 (57) \\
\hline \multirow[t]{3}{*}{$\mathrm{C}^{\varepsilon 115,76-\mathrm{NH}_{2} \mathrm{RNase} A}$} & 1.7 (14) & & $3.5(-29)$ & $7.2(61)$ \\
\hline & \multicolumn{3}{|c|}{$\mathbf{p H} * \mathbf{3}^{2}$} & \\
\hline & $\begin{array}{l}k_{1}(\text { AMP })^{2} \\
X 10^{3}\end{array}$ & $\begin{array}{l}{ }^{3} \mathrm{SD} \\
\times 10^{4}\end{array}$ & $\begin{array}{l}k_{2}(\text { AMP) } \\
\times 10^{4}\end{array}$ & $\begin{array}{l}S D \\
\times 10^{5}\end{array}$ \\
\hline $\mathrm{C}^{\varepsilon 115-\mathrm{NH}_{2} \mathrm{RNase} A}$ & 3.4 (43) & 7.7 & 1.2 (57) & 4.3 \\
\hline $\mathrm{C}^{\varepsilon 115,76-\mathrm{NH}_{2} \text { RNase A }}$ & $4.4(34)$ & 2.3 & $1.2(66)$ & 7.1 \\
\hline
\end{tabular}

${ }^{1}$ Data taken from Puntambekar (1991), the amplitudes are given in parentheses and represent the percentages of total expected amplitude (see text).

${ }^{2}$ The amplitudes given in the parentheses are the percentages of the total observed amplitude (the sum of the two phases $=100 \%$ ).

${ }^{3} \mathrm{SD}$ is the standard deviation obtained for the rate constants. 
amplitudes given for the $\mathrm{pH}^{*} 3$ experiments cannot be directly compared to those obtained at $\mathrm{pH}^{*} 6$, as the former represent percentages of the total observed, whereas the latter represents the percent of the total expected. The total amplitude expected represents the difference between the emission amplitude of the denatured state and the corresponding amplitude for the native state. Experimental problems at $\mathrm{pH}^{*} 3$ (see above) prevented the measurement of the emission amplitude of the denatured state.

Examination of Table 2 reveals several significant differences between the kinetics obtained at $\mathrm{pH}^{\star} 3$ to those obtained at $\mathrm{pH}^{*} 6$. First of all, the kinetics are biphasic at $\mathrm{pH}^{*} 3$ and triphasic at $\mathrm{pH}^{*} 6$. Also, the phase associated with an increase in fluorescence (negative amplitude) observed at $\mathrm{pH}^{*} 6$ is not observed at $\mathrm{pH}^{\star} 3$. One can interpret this in two different ways. This result could mean that this event does not occur at $\mathrm{pH}^{\star} 3$; examination of model compounds at $\mathrm{pH}^{\star} 3$ should shed some light on this possibility. It could also mean that this phase either increases or decreases in rate such that it severely overlaps one of the other kinetic phases of larger amplitude and thus cannot be independently observed. This would serve to decrease the observed amplitude for the large amplitude phase and alter the value of the observed rate constant.

Comparison of the rate constants obtained from the different sets of experiments suggest that the fastest phases observed at both $\mathrm{pH}$ values represent the same process. The slowest phase observed at $\mathrm{pH}^{\star} 3$ has an associated rate constant that is between that for the second and third phase obtained from the $\mathrm{pH}^{\star} 6$ experiments. One interpretation of this result is that the slowest process 
observed at $\mathrm{pH}^{\star} 6$ becomes faster at $\mathrm{pH}^{*} 3$. However, previous work (Puntambekar, 1991) strongly suggests that the slowest phase in $\mathrm{pH}^{*} 6$ folding represents the trans to cis isomerization of Pro-114 and other studies have shown that the isomerization event for proline in model compounds and for Pro-93 in unmodified RNase $\mathrm{A}$ are $\mathrm{pH}$ independent. If the observations for model compounds and Pro-93 are universal, then the slowest phases observed for aminated RNases at $\mathrm{pH}^{*} 3$ and $\mathrm{pH}^{*} 6$ could not represent the isomerization of Pro-114. However, the universal nature of the $\mathrm{pH}$ independence of proline isomerization has not been shown.

Another possible explanation is that the second phase observed at $\mathrm{pH}^{*} 6$ becomes slower at $\mathrm{pH}^{*} 3$ to the point where it severely overlaps the slowest process. If this phase is less than a factor of two faster than the slowest phase, then the two processes will be observed as a single phase and the apparent rate constant for the composite will be larger than the actual rate for the slowest process. In addition, since the faster process is associated with an increase in fluorescence and the slower with a decrease in fluorescence of larger magnitude, the apparent amplitude will be smaller than the actual amplitude for the slowest process. Assuming that this occurs and that the fastest processes observed for experiments at both $\mathrm{pH}^{\star} 3$ and $\mathrm{pH}^{\star} 6$ represent the same event, then one would expect to observe biphasic kinetics at $\mathrm{pH}^{*} 3$ with relative amplitudes for the slowest and fastest process of two to one respectively. This is precisely what is observed for the folding of $\mathrm{C}^{\varepsilon 115,76-\mathrm{NH}_{2}}$ RNase $\mathrm{A}$. However, the ratio observed for 
the folding of $\mathrm{C}^{\varepsilon 115-\mathrm{NH}_{2}} \mathrm{RNase} A$ is somewhat lower. Although the data is reasonably consistent with this explanation, only examination of the folding kinetics at $\mathrm{pH}$ values between 3 and 6 will yield a definitive answer.

\subsection{Fluorescence Energy Transfer}

Normally, the refolding of RNase A shows the decrease in amplitude when monitored by tyrosine fluorescence, as the excited state is quenched by local groups in the refolded protein. A deviation from this general observation occurred when the aminated derivatives of RNase $A\left(C^{\varepsilon 115-N_{2}}\right.$ RNase $A$ and $\mathrm{C}^{\left.\varepsilon 115,76-\mathrm{NH}_{2}\right)}$ were refolded at $\mathrm{pH}^{*} 6,-15^{\circ} \mathrm{C}, 35 \%(\mathrm{v} / \mathrm{v})$ methanol cryosolvent (Puntambekar, 1991). Here, the fluorescence increased in the second kinetic phase and markedly so (Figure 3 ). One of the possible causes of this unique fluorescence increase is fluorescence energy transfer between fluorophores in the protein.

The energy absorbed by one fluorophore can be transferred to another distant fluorophore in particular situations. This process can occur when the emission spectra of the donor and the excitation spectra of the acceptor overlap. Further, energy can be transferred from donor to acceptor that are as far apart as 70 Angstroms from one other (Stryer, 1968, 1978). As mentioned above RNase A has six tyrosine residues. It is possible that one of the unmodified tyrosine residues might be transferring energy to the aminotyrosine in $\mathrm{C}^{\varepsilon 115-\mathrm{NH}_{2}} \mathrm{RNase} A$ 
and to one or both of the aminotyrosine in $\mathrm{C}^{\varepsilon 115,76-\mathrm{NH}_{2}} \mathrm{RNase} \mathrm{A}$, and in doing so, give rise to a fluorescence increase. To examine the possibility that fluorescence energy transfer can occur between tyrosine and aminotyrosine, model compounds and the aminated proteins were studied under the same conditions as the folding experiment.

\subsubsection{Model Compounds}

The model compounds examined were $\mathrm{N}$-acetyl-L-tyrosine ethyl ester (ATEE) that mimics the tyrosine residue in the protein and 3-amino-L-tyrosine (AT) that mimics aminotyrosine. If an energy transfer occurs in a mixture of the two, there should be an increase in an intensity and a shift in the excitation maxima of the amino tyrosine. In this study, the concentration of ATEE was varied while the concentration of the aminotyrosine was held constant.

The excitation spectra of the mixture of these molecules in different ratios of ATEE to AT is presented in Figure 13. The emission wavelength was set to 350 $\mathrm{nm}$. The excitation spectra show a significant blue shift (290 nm to $286 \mathrm{~nm}$ ) and an increase in intensity at excitation maximum with increasing tyrosine concentrations. Figure 14 shows the corresponding emission spectra. The spectra are fairly constant in amplitude and have the same maximum.

The fact that the excitation spectra blue shift and the emission maximum remain constant indicates that fluorescence energy transfer is occurring. The rationale for this is explained in the section below. The constant amplitude 


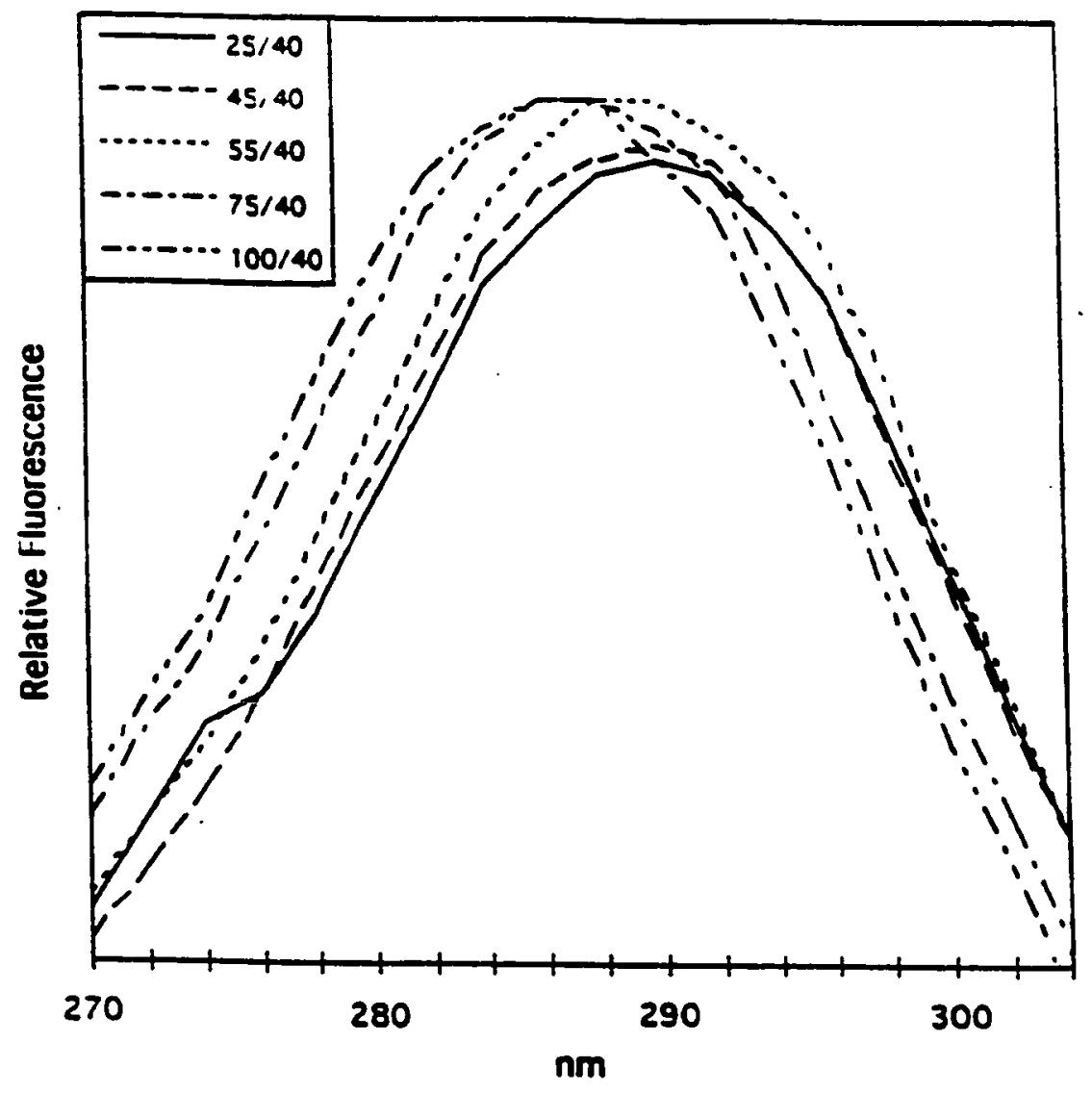

FIGURB 13 : Excitation spectra of the mixtures of acetyltyrosine ethyl ester (ATEE) and aminotyrosine (AT), in $35 \%$ methanol, $-15^{\circ} \mathrm{C}$ and $\mathrm{pH}^{\star} 6$. The emission wavelength was set to $350 \mathrm{~nm}$. The figure legend gives the ratio of ATEE/AT in $\mu \mathrm{M}$. 


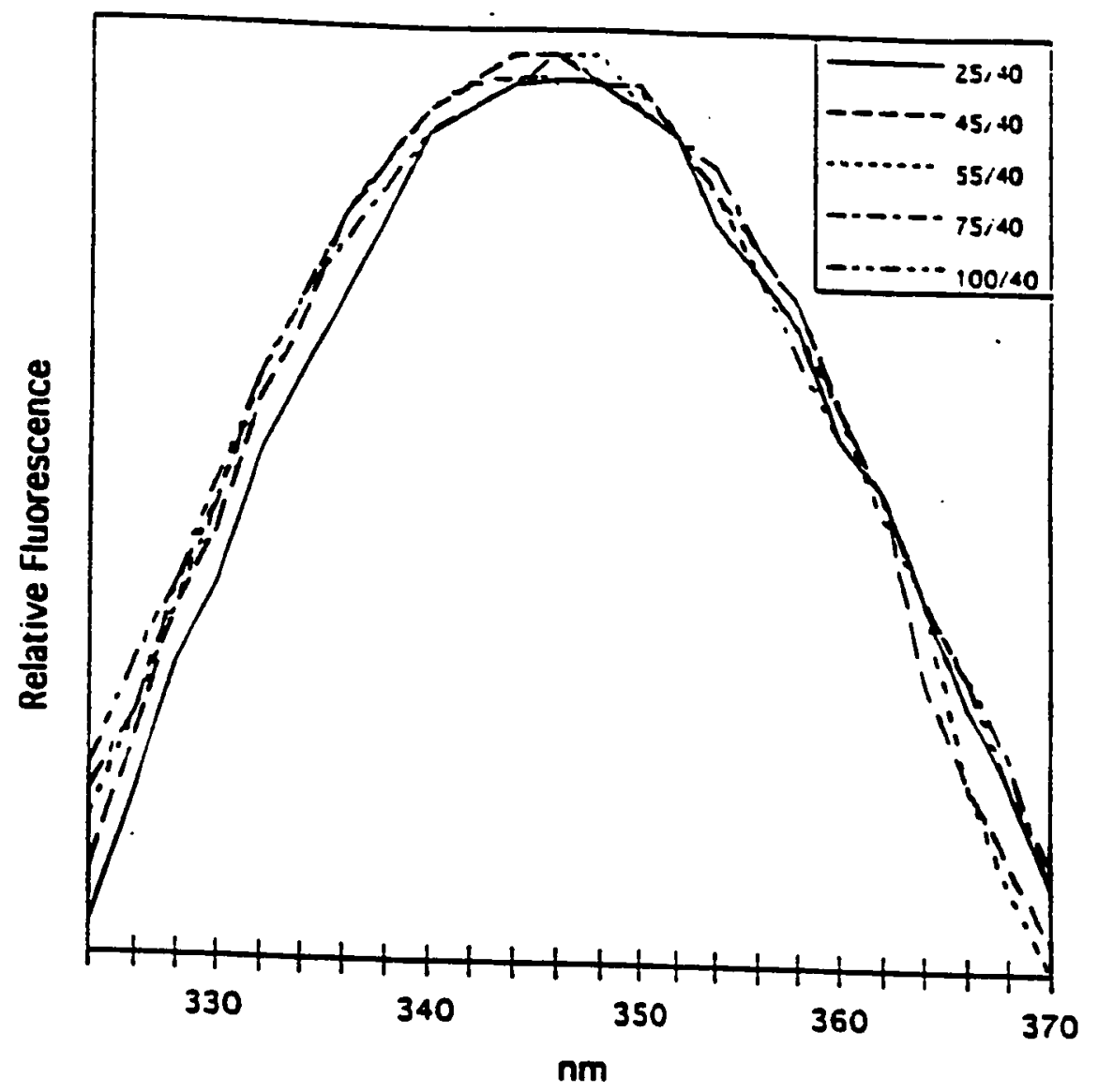

FIGURE 14: Emission spectra of the mixture of acetyltyrosine ethyl ester (ATEE) and aminotyrosine (AT), in $35 \%$ methanol, $-15^{\circ} \mathrm{C}$ and $\mathrm{pH}{ }^{\star} 6$. The excitation wavelength was set to $288 \mathrm{~nm}$. The figure legend gives the ratio of ATEE/AT in $\mu \mathrm{M}$. 
observed for the emission is due to the fact that the excitation wavelength was chosen at the isosbestic point of the excitation spectra.

\subsubsection{Aminotyrosyl RNases}

The emission and excitation spectra for amino-derivatives of RNase A were scanned periodically after initiation of folding at $\mathrm{pH}^{*} 6$ to examine the possibility of fluorescence energy transfer. The excitation and emission spectra of the native derivatives and $6 \mathrm{M}$ guanidine hydrochloride unfolded derivatives were also measured.

\subsubsection{1 $\mathrm{C}^{\varepsilon 115-\mathrm{NH}_{2}}$ RNase A.}

Figure 15 shows the excitation spectra for $\mathrm{C}^{\varepsilon 115-\mathrm{NH}_{2}} \mathrm{RNase} A$ (emission wavelength of $296 \mathrm{~nm}$ ) as a function of folding time. The excitation maxima for denatured $C^{\varepsilon 115-\mathrm{NH}_{2}} \mathrm{RNase} A$ and native $C^{\varepsilon 115-\mathrm{NH}_{2}}$ RNase $A, 288 \mathrm{~nm}$ and $298 \mathrm{~nm}$, respectively, are also given in the figure for comparison. Early in folding (2940 \& $6000 \mathrm{sec}$ ), the excitation spectra show two maxima at $288 \mathrm{~nm}$ and $298 \mathrm{~nm}$, one similar to that for the native protein and one similar to that for denatured protein. As folding proceeds, the amplitude at $298 \mathrm{~nm}$ maxima is lost, and at some time between the last measurement $(18000 \mathrm{sec})$ and the final folded state, the $288 \mathrm{~nm}$ maximum shifts back to $298 \mathrm{~nm}$.

The emission spectra obtained by periodic scanning during folding is shown in Figure 16. The emission maxima for denatured $\mathrm{C}^{\varepsilon 115-\mathrm{NH}_{2}} \mathrm{RNase} A$ and 


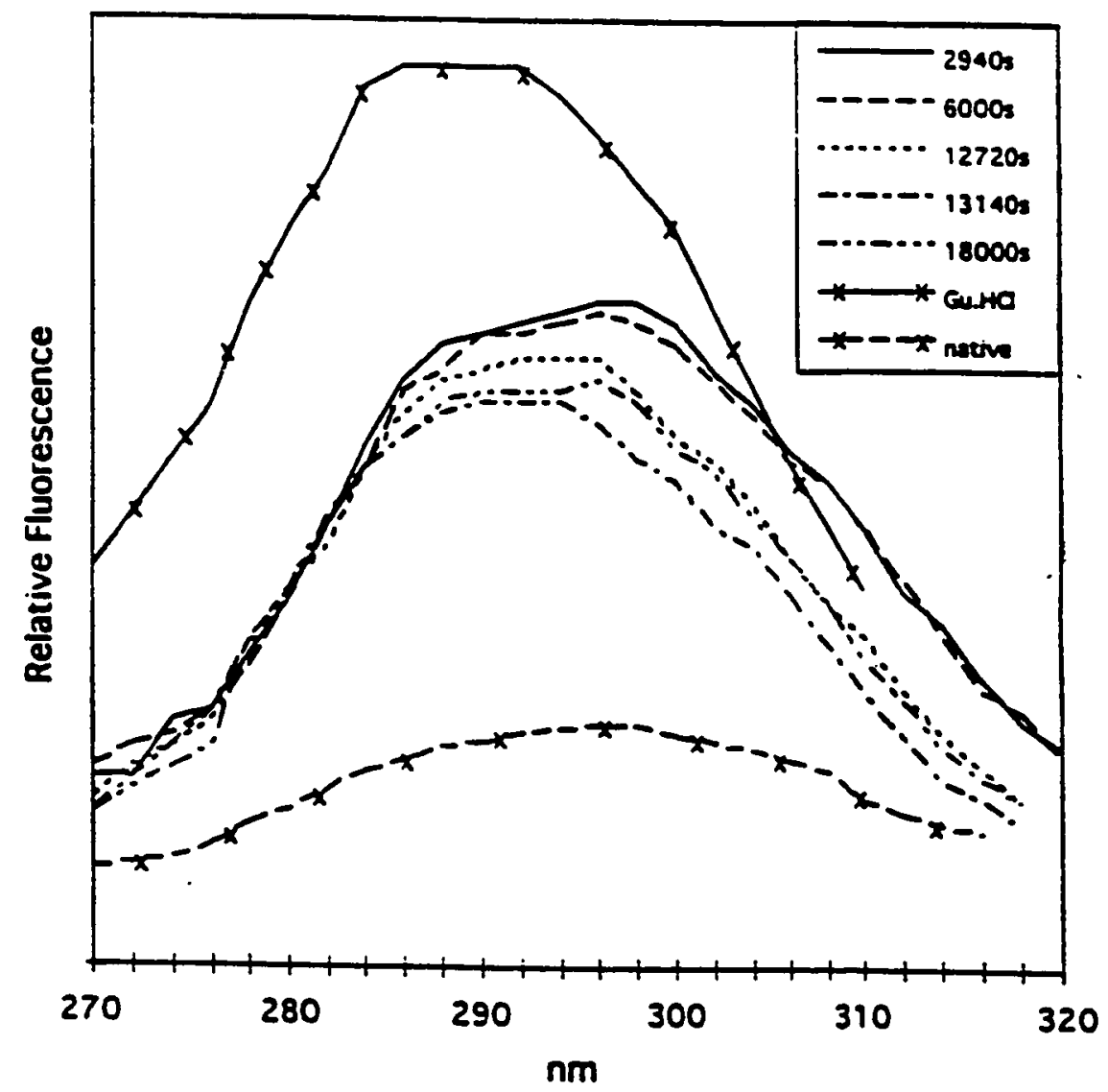

FGURE 15 : Excitation spectra of $\mathrm{C}^{\varepsilon 115-\mathrm{NH}_{2}} \mathrm{RNase} \mathrm{A}(14 \mu \mathrm{M})$ in $35 \%$ methanol, $-15^{\circ} \mathrm{C}$ and $\mathrm{pH}^{\star} 6$ (emission wavelength of $390 \mathrm{~nm}$ ) as a function of folding time. The figure legend indicates the folding time at which the spectral scan was initiated. Native and guanidine hydrochloride unfolded (Gu.HCl) $\mathrm{C}^{\varepsilon 115-\mathrm{NH}_{2}} \mathrm{RNase}$ $A(14 \mu \mathrm{M})$ are also included. 


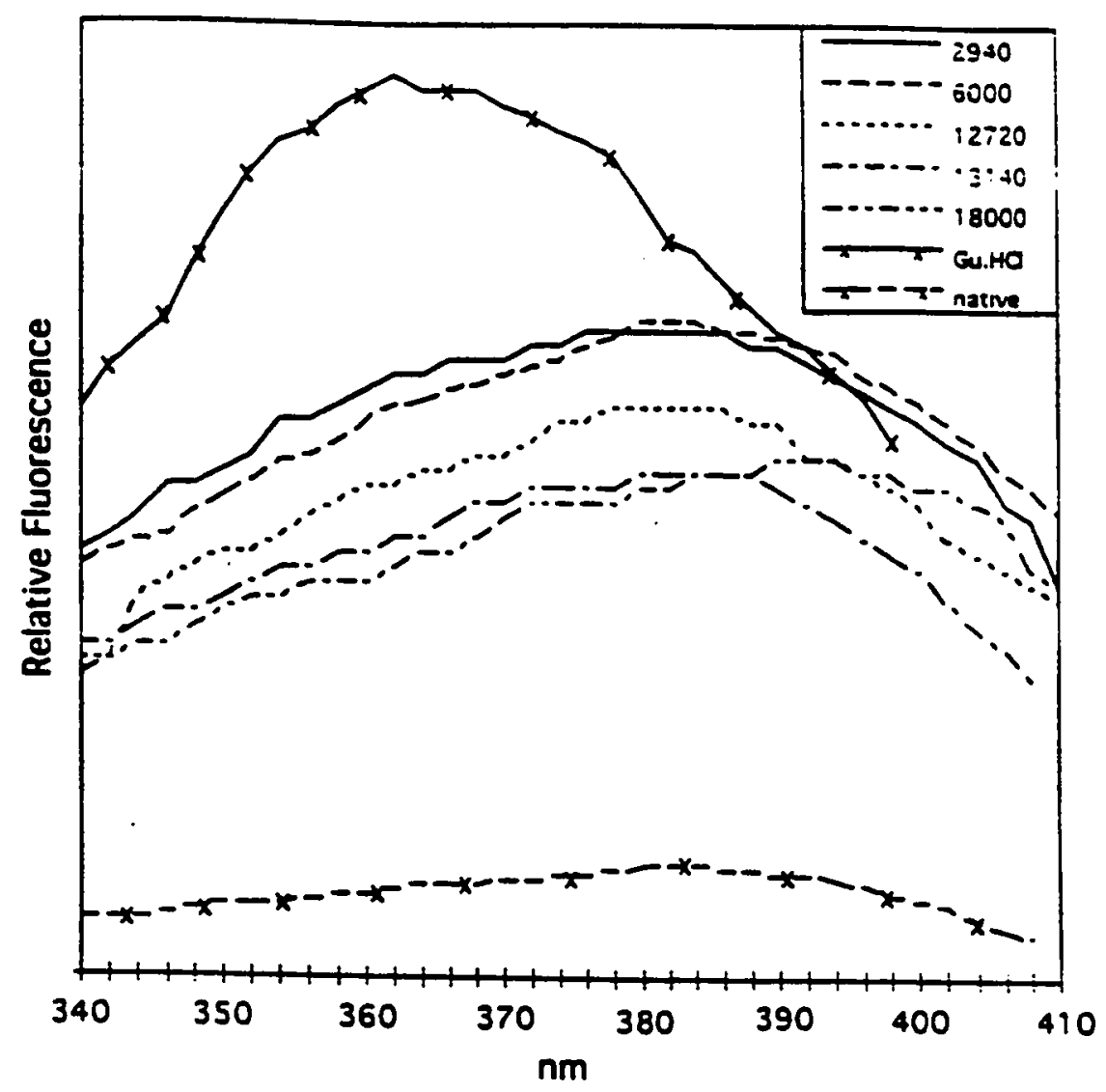

FIGURE 16 : Emission spectra of $\mathrm{C}^{\varepsilon 115-\mathrm{NH}_{2}}$ RNase A (14 $\left.\mu \mathrm{M}\right)$, in $35 \%$ methanol, $-15{ }^{\circ} \mathrm{C}$ and $\mathrm{pH}^{*} 6$ (excited at $296 \mathrm{~nm}$ ) as a function of folding time. The figure legend indicates the folding time at which the spectral scan was initiated. The spectra of native and guanidine hydrochloride unfolded $(\mathrm{Gu} . \mathrm{HCl}) \mathrm{C}^{\varepsilon 115-\mathrm{NH}_{2}} \mathrm{RNase}$ $A(14 \mu \mathrm{M})$ are also included. 
native $C^{\varepsilon 115-\mathrm{NH}_{2}}$ RNase $A, 364 \mathrm{~nm}$ and $384 \mathrm{~nm}$, respectively, are also shown in this figure. All spectra obtained during the folding process have the same maxima

observed for native $\mathrm{C}^{\varepsilon 115-\mathrm{NH}_{2}} \mathrm{RNase} \mathrm{A}$.

The shifting of the excitation maxima is consistent with the formation of an abortive intermediate. Two maxima are observed early in folding. The long-wavelength maxima is coincident with that observed for the native state and the short-wavelength maximum is coincident with that observed for the denatured state. Later, the amplitude for long-wavelength maxima is lost and short-wavelength maximum remains. This is consistent with the formation of a folded state early in folding that must be subsequently unfolded to another intermediate to allow further folding to proceed. Hence, the formation of the folded intermediate must be aborted and continued folding proceeds along a different path. The completion of folding is accompanied by a shifting of the maximum to the long-wavelength maximum given by the native state. Thus, the less folded intermediate must become more compact in order to reach the native state. Although the excitation spectra are consistent with the formation of an abortive intermediate, the emission spectra are not. In this model, changes in the excitation maxima should be accompanied by changes in the emission maxima, as changes in the solvent environment should affect both the ground and excited state. Since the emission maxima remain constant throughout the folding process, the data does not support the abortive intermediate model.

A second possibility is that changes in structure that accompany folding 


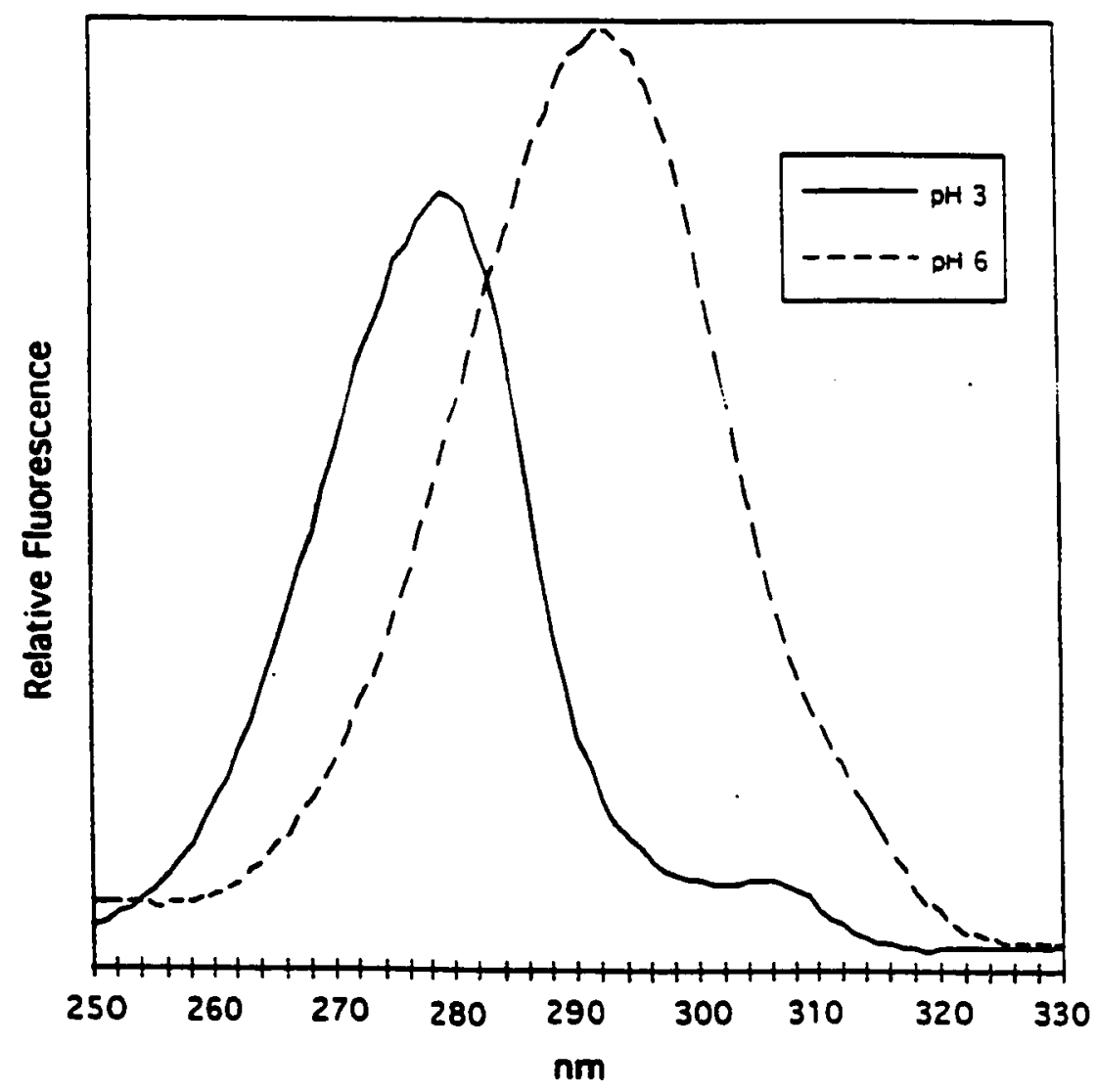

FIGURE 17 : Excitation spectra of $\varepsilon$-Aminotyrosine at $\mathrm{pH}^{*} 3$ and $\mathrm{pH}^{*} 6$ in aqueous solution at room temperature. 


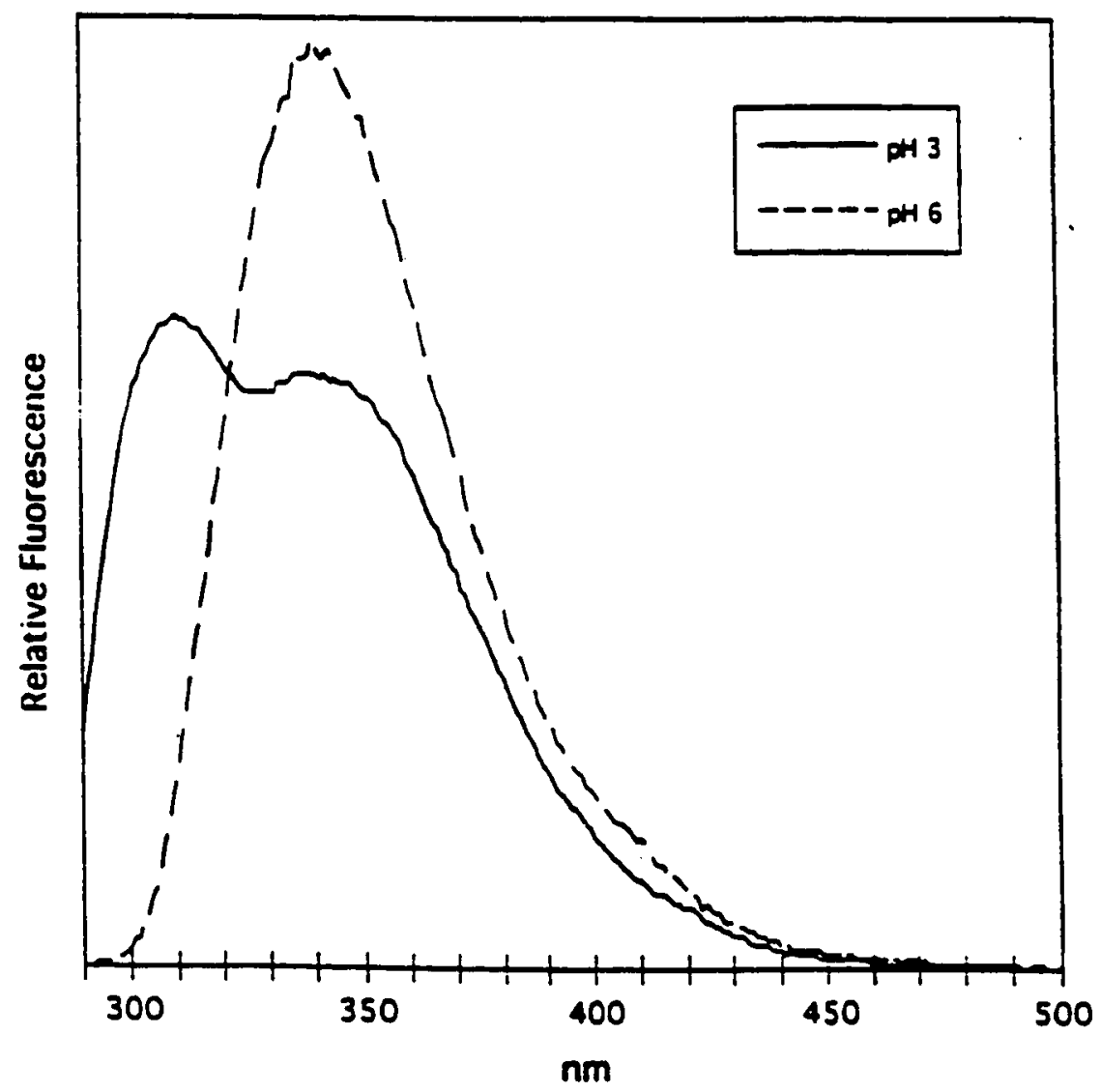

FIGURE 18 : Emission spectra of $\varepsilon$-Aminotyrosine at $\mathrm{pH}^{\star} 3$ and $\mathrm{pH}^{\star} 6$ in aqueous solution at room temperature. 
serve to alter the $\mathrm{pK}$ of the aminotyrosyl group. The excitation spectra for the aminotyrosyl group is highly dependent on the ionization state of the amino functionality. Protonation of the amino group serves to shift the excitation spectrum to shorter wavelengths (Figure 17). The $\mathrm{pK}$ of the amino groups in aminophenols are typically near 4.9. Since this experiment was performed at $\mathrm{pH}^{*}$ 6 , an increase in the $\mathrm{pK}$ as small as 0.5 units should have a significant effect on the population of the protonated and deprotonated states and hence on the excitation spectrum. Comparison of the excitation spectra for $\varepsilon$-aminotyrosine to the spectra obtained early in folding show this to be a possibility, as the wavelength maxima for the protonated and deprotonated states compare well with the two maxima in the protein spectra. However, the ionization state of $\varepsilon$-aminotyrosine also shifts the emission maximum to shorter wavelength (Figure 18). Again, such changes in the emission spectra for the protein were not observed and thus the data does not support this model.

A third possibility is that fluorescence energy transfer is involved. It has been previously established that the fluorescence emission spectrum for tyrosine has significant overlap with the excitation spectrum for amino tyrosine (Punthambekar, 1991). In situations such as this, excitation of the donor species (tyrosine in this particular case) can result in an energy transfer to the acceptor species (aminotyrosine in this particular case). The net result is a decrease in the fluorescence emission of the donor species and an enhanced fluorescence emission from the acceptor species with an emission maximum characteristic of the acceptor species. The degree of enhancement depends primarily on the amount of 
overlap between the respective emission and excitation spectra, the distance between the species, the concentration of the donor species, the quantum yield for the donor species, and the nature of the media surrounding the species. At the excitation wavelength used for the $\mathrm{pH}^{*} 6$ kinetics experiments, $288 \mathrm{~nm}$, both tyrosine and aminotyrosine absorb. Thus, the emission amplitude for aminotyrosine residues in aminated RNase A will depend not only on the quantum yield for the aminotyrosine itself, but the amount of energy transfer that occurs.

Fluorescence energy transfer events can be readily monitored through the excitation spectrum. In experiments such as these, the emission is set to a wavelength where only the donor species emits and the excitation spectra are scanned over the excitation bands for both the donor and acceptor species. If energy transfer does not occuir to any appreciable degree, the excitation spectrum will be characteristic only of the acceptor species. If, however, energy transfer is significant, the excitation spectrum will be characteristic of both the donor and acceptor species.

The potential for energy transfer between iyrosine and aminotyrosine was examined with model compounds. Figure 13 gives the excitation spectra for solutions containing a fixed amount of aminotyrosine and varying amount of $\mathrm{N}$-acetyltyrosine ethyl ester. The emission wavelength was set to $350 \mathrm{~nm}$ where only aminotyrosine emits. The figure clearly shows that increasing concentrations of of $\mathrm{N}$-acetyltyrosine ethyl ester serve to shift the excitation spectrum from the long wavelength excitation maximum for aminotyrosine $(290 \mathrm{~nm})$ towards the 


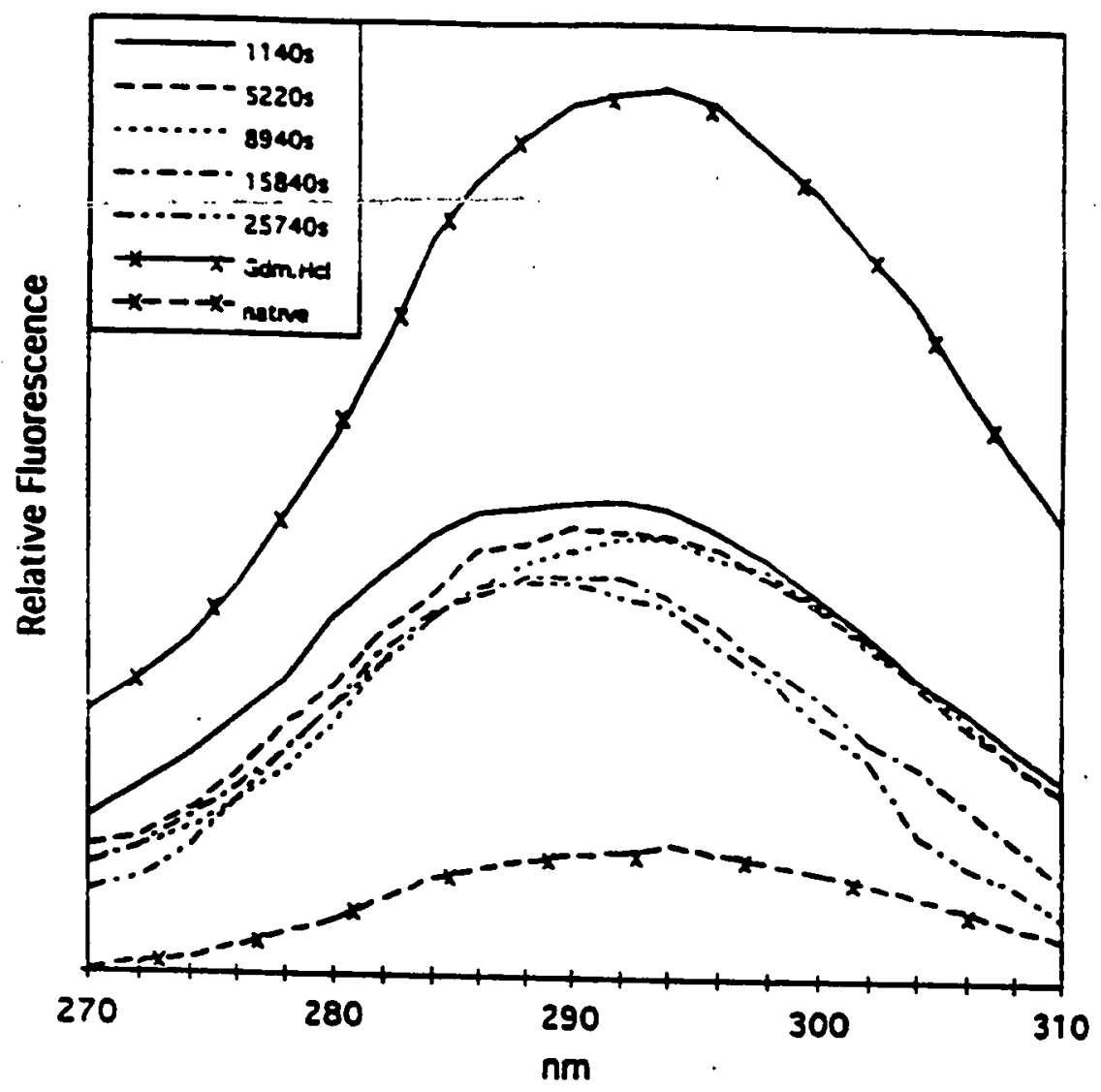

FIGÜR 19 : Excitation spectra of $\mathrm{C}^{\varepsilon 115.76-\mathrm{NH}_{2}}$ RNase A $(14 \mu \mathrm{M})$ in $35 \%$ methanol, $-15^{\circ} \mathrm{C}$ and $\mathrm{pH}^{*} 6$ (emission wavelength of $350 \mathrm{~nm}$ ) as a function of folding time. The figure legend indicates the folding time at which the spectral scan was initiated. The spectra for native and guanidine hydrochloride unfolded (Gu.HCl) $C^{1115,76-\mathrm{NH}_{2}}$ RNase $\mathrm{A}(14 \mu \mathrm{M})$ are included. 
shorter wavelength excitation maximum for $\mathrm{N}$-acetyltyrosine ethyl ester (275 $\mathrm{nm}$ ). This is precisely what one would expect to observe for energy transfer between these two species. One would not expect to observe independent maxima, as the excitation bands for these species are broad and severely overlap.

The excitation maxima for $\mathrm{C}^{\varepsilon 115-\mathrm{NH}_{2}}$ RNase A ( Figure 15) show precisely those changes observed for the model compounds, but in a time dependent manner. This indicates that fluorescence energy transfer between an unmodified tyrosine and the aminotyrosine moiety may explain the kinetic data. This is supported by the fact that the emission maxima remain constant throughout the folding process and that energy transfer does not alter the emission maximum of the acceptor species. By the process of elimination, it appears that fluorescence energy transfer is the most probable explanation. In this light, we believe that the protein initially folds to a species where energy transfer is diminished and thus the excitation maxima is more characteristic of aminotyrosine. Later in folding, the local structure changes in a manner that enhances the transfer and the excitation band shifts to shorter wavelength. The final steps in folding involve the decomposition of these species in to the native structure where transfer is diminished again and thus the excitation maxima shift to longer wavelengths.

3.4.2.2 $\mathrm{C}^{\varepsilon 115,76-\mathrm{NH}_{2}}$ RNase A

The excitation spectra of $C^{\varepsilon 115,76-\mathrm{NH}_{2}}$ RNase $A$ are shown in Figure 19. The spectral shifts observed for this derivative are similar to that observed for 
$\mathrm{C}^{\varepsilon 115-\mathrm{NH}_{2}}$ RNase A, but of smaller magnitude. The excitation maxima for denatured $C^{\varepsilon 115,76-\mathrm{NH}_{2}}$ RNase A and native $C^{\varepsilon 115,76-\mathrm{NH}_{2}}$ RNase $\mathrm{A}, 292 \mathrm{~nm}$ and 294 $\mathrm{nm}$ respectively, are also shown in this figure. Early in folding (1140 sec, 5220, \& $8940 \mathrm{sec}$ ), the excitation spectra show two maxima at $286 \mathrm{~nm}$ and $294 \mathrm{~nm}$, one similar to that for native protein and one similar to that for denatured protein. The $296 \mathrm{~nm}$ maxima appear as a shoulder on the larger $294 \mathrm{~nm}$ band. As folding proceeds, the amplitude at $294 \mathrm{~nm}$ maxima is lost. At some time between the last measurement $(25740 \mathrm{sec}$ ) and the final folded state, the $286 \mathrm{~nm}$ shifts back to $294 \mathrm{~nm}$.

The emission maxima (Figure 20) for denatured $\mathrm{C}^{\varepsilon 115,76-\mathrm{NH}_{2}} \mathrm{RNase} A$ and native $C^{\varepsilon 115,76-\mathrm{NH}_{2}} \mathrm{RNase} A$ are $358 \mathrm{~nm}$ and $362 \mathrm{~nm}$ respectively. With the exception of the spectrum obtained at $25740 \mathrm{sec}$, all spectra obtained during the folding process have the same maxima observed for native $\mathrm{C}^{\varepsilon 115,76-\mathrm{NH}_{2}} \mathrm{RNase} A$. The emission spectrum obtained at $25740 \mathrm{sec}$ appears to have a maximum at 354 $\mathrm{nm}$ and remains unexplained.

The shifting of the excitation maxima and the stability of the emission maxima indicate that the aforementioned energy transfer model can be applied to the folding of this derivative as well. The diminished magnitude of the shifting indicates that the excitation spectrum for second aminated residue, aminotyrosine-76, does not change with time and thus is not involved in energy 


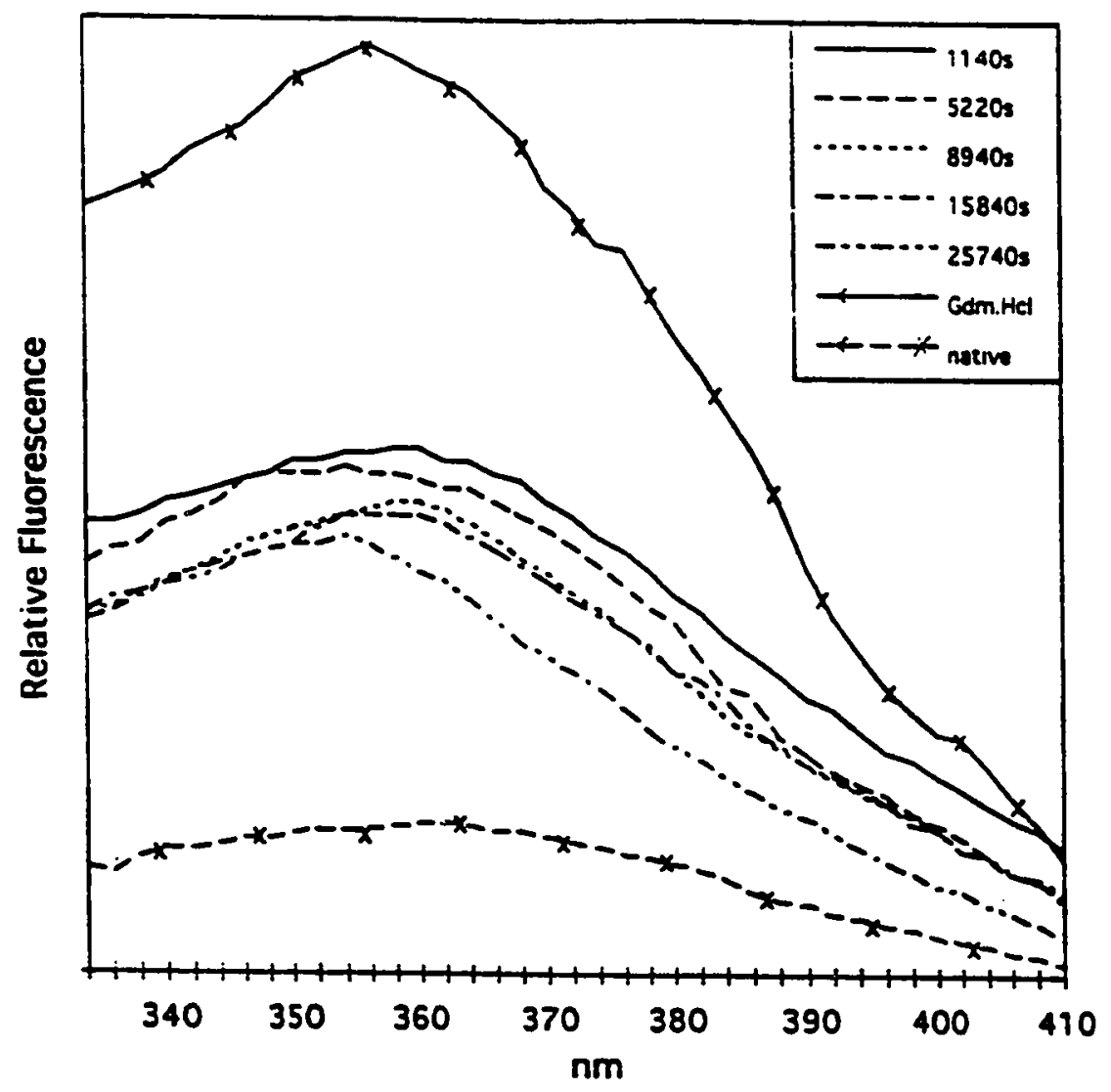

FIGURE 20 : Emission spectra of $\mathrm{C}^{\varepsilon 115,76-\mathrm{NH}_{2}}$ RNase A $(14 \mu \mathrm{M})$ in 35\% methanol, $-15^{\circ} \mathrm{C}$ and $\mathrm{pH}{ }^{\star} 6$ (excitation wavelength of $288 \mathrm{~nm}$ ) as a function of folding time. The figure legend indicates the folding time at which the spectral scan was initiated. Native and guanidine hydrochloride unfolded (Gu. $\mathrm{HCl}$ ) $\mathrm{C}^{\varepsilon 115,76-\mathrm{NH}_{2}} \mathrm{RNase} \mathrm{A}(14 \mu \mathrm{M})$ are included. 
transfer. In addition, since energy transfer is still observed for aminotyrosine

-115 , Tyr-76 is most likely not involved in energy transfer in $\mathrm{C}^{\varepsilon 115-\mathrm{NH}_{2}} \mathrm{RNase} A$.

\section{CONCLUSION}

RNase A contains six tyrosines that serve as intrinsic absorbance and fluorescence probes of structure. However, the probes only provide a global picture of the folding process. Chemical modifications at specific sites, on the other hand, offer information about particular regions. From previous kinetic studies of nitrotyrosyl and aminotyrosyl RNases at $\mathrm{pH}^{*} 6$ and subzero temperature, some knowledge has been gained about the pathway through which this protein folds. In addition, unique kinetics were observed. In this project the subzero temperature studies were extended to $\mathrm{pH}^{\star} 3$ and the unique fluorescence increase observed in $\mathrm{pH}^{*} 6$ was examined.

The reoxidation of the amino-derivatives to corresponding nitro-derivatives of RNase A has been successfully prevented by both degassing with vacuum and nitrogen purging. The folding experiments were performed using the degassing protocol.

Investigation of model compounds support the possibility of fluorescence energy transfer. Analysis of the excitation and emission spectra obtained by periodic scanning during folding of aminated RNases, strongly support that energy transfer is taking place during folding of amino-derivatives of RNase A at $\mathrm{pH}^{*} 6$. 
The equilibrium unfolding of both $C^{\varepsilon 115-\mathrm{NH}_{2}} \mathrm{RNase} A$ and $\mathrm{C}^{\varepsilon 115,76-\mathrm{NH}_{2}}$ RNase $A$ with guanidine hydrochloride and urea failed because of quenching problems. The denaturant must play a role in quenching the aminotyrosine fluorescence in $35 \%$ methanol, at $\mathrm{pH}^{*} 3$ and $-15^{\circ} \mathrm{C}$.

The folding of both amino-derivatives of RNase $\mathrm{A}$ at $-15^{\circ} \mathrm{C}$ and $\mathrm{pH} \mathrm{H}^{*} 3$ shows biphasic kinetics. The rate constants are similar for the two derivatives. Comparison of this result with previous studies indicates that the slowest phase obtained in the refolding of these proteins is $\mathrm{pH}$ dependent between $\mathrm{pH}^{*} 3$ and $\mathrm{pH}^{\star} 6$, suggesting that the slowest process is not associated with proline isomerization. However, the change in rate for other processes may explain the result as well. 


\section{REFERENCES}

Adler, M.; Scheraga, H. A. Biochemistry 1990, 29, 8211.

Biringer, R. G.; Fink, A. L. Biochemistry 1982, 21,4748 .

Biringer, R. G.; Fink, A. L. Biochemistry 1988a, 27, 301.

Biringer, R. G.; Fink, A. L. Biochemistry 1988b, 27, 315.

Biringer, R. G.; Fink, A. L.; Austin, C. M. Biochemistry 1988, 27, 311.

Biringer, R. G.; Puntambekar, B. Biophys. J. 1991, 59, 488 a.

Brand, L.; Bernard, W. Methods of enzymology 1967 11, 776.

Brandts, J. F.; Halvorson, H. R.; Brennan, M. Biochemistry 1975, 14, 4953.

Chou, P. Y.; Fasman , G. D. Adv. Enzymol. 1978, 47, 45.

Cook, K. H.; Schmid, F. X.; Baldwin, R. L. Proc. Natl. Acad. sci. USA 1979, 76 (12), 6157.

Dubchak I.; Hollbrook S. R.; Kim, S. Proteins: Structure, Function, and genetics $1993,16,79$.

Francoise, F. D; Pezolet, M. Biochemistry 1990, 29, 8771.

Garel, J. R.; Baldwin, R. L. Proc. Natl. Acad. sci. USA 1973, 70, 3347.

Guggenheim, E. A. Phil. Mag. 1926, 2, 538.

Hendrickson, W. A., Protein Engineering; Alan R. Liss: New York, 1987; pp 5-13.

Hendsch, Z. S.; Tidor B. Protein Science 1994, 3, 211.

Houry, W. A.; Rothwarf, D. M.; Scheraga H. A. Biochemistry 1994, 33, 2516.

Kim P.; Baldwin, R. Ann. Rev. Bioch. 1982, 51, 459.

Levinthal, C. J. chim. Phys. 1968, 65, 44.

Lin, L. N.; Brandts, J. F. Biochemistry 1983, 22, 573.

Lin, L. N.; Brandts, J. F. Biochemistry 1984, 23, 5713. 
Lin, L. N.; Brandts, J. F. Biochemistry 1983, 22, 559.

Puntambekar, B. Thesis, San Jose State University, Aug. 1991.

Privalov, P. L. Adv. Protein Chem. 1979, 33, 167.

Privalov, P. L; Gill, S. J. Adv. Protein Chem. 1988, 39, 193.

Privalov, P. L.; Khechinashvili, N. N. J. Mol. Biol. 1974, 86, 665.

Schmid, F. X. Eur. J. Biochem. 1981, 114, 105.

Schmid, F. X.; Blaschek, H. Eur. J. Biochem. 1981, 114, 111.

Schmid, F. X. Eur. J. Biochem. 1982, 128, 77.

Schmid, F. X. Biochemistry 1983, 22, 4690.

Schulz, D.A.; Schmid, F. X.; Baldwin, R. L. Science 1992, 1, 917.

Stryer, L. Science 1968, 162, 526.

Stryer, L. ann. rev. Biochem. 1978, 47, 819.

Stokkum, I. H. M.; Spoelder, H. J. W.; Bloemendal, M.; Grondelle, R.; Groen, F. C. Analytical Biochemistry 1990, 191, 110.

Stokkum, I. H. M.; Pribic R., Chapman, D.; Haris, P. I.; Bloemendal, M. Analytical Biochemistry 1993, 214, 366.

Wetlaufer, D. B. Proc. Natl. Acad. Sci. USA 1973, 70, 697. 